\title{
METODOLOGIAS PARA A OBTENÇÃO DE PARÂMETROS UTILIZADOS EM MODELOS DE INFILTRAÇÃO DA ÁGUA NO SOLO
}

\author{
PABlo JAVIER GHIBERTO
}

Engenheiro Agrônomo

Orientador: Prof. Dr. SERGIO OLIVEIRA MORAES

Dissertação apresentada à Escola Superior de Agricultura "Luiz de Queiroz", Universidade de São Paulo, para obtenção do título de Mestre em Agronomia, Área de Concentração: Solos e Nutrição de Plantas

P I R A C I C A B A

Estado de São Paulo - Brasil

Maio - 1999 
Dados Internacionais de Catalogaçāo na Publicaçāo (CIP) DIVISĀo DE BIBLIOTECA E DOCUMENTAÇĀO - Campus "Luiz de Queiroz"/USP

\author{
Ghiberto, Pablo Javier \\ Metodologias para a obtenção de parâmentros utilizados em modelos de \\ infiltração da água no solo. / Pablo Javier Ghiberto. - - Piracicaba, 1999.
}

79 p. : il.

Dissertação (mestrado) - - Escola Superior de Agricultura Luiz de Queiroz, 1999. Bibliografia.

1. Condutividade hidráulica 2. Drenagem 3. Infiltração 4. Infiltrômetro 5. Relaçāo solo-água I. Titulo

CDD 631.432 


\section{AGRADECIMENTOS}

Ao Prof. Doutor Sérgio Oliveira Moraes pela orientação no trabalho, tempo dedicado à minha formação, constante apoio e amizade.

Aos Professores Paulo Leonel Libardi, Quirijn de Jong Van Lier da ESALQ/USP e ao Professor Miguel Ángel Pilatti da Universidade Nacional do Litoral (UNL, Argentina) pelos ensinamentos, incentivo no trabalho e amizade.

À Faculdade de Ciências Agrárias da UNL por ter me dado a possibilidade da realização deste curso.

Ao Conselho do Curso Solos e Nutrição de Plantas ESALQ/USP por ter me aceitado como aluno.

Ao Cláudio Roberto Marciano e Fernando Carvalho Oliveira pela ajuda na fase experimental.

Ao Luiz Fernando Novello e Francisco Bernardo Dias pela constante ajuda e amizade.

Aos Professores da Faculdade de Ciências Agrárias de Esperanza Carlos Daniel Giaveno, Jorge de Orellana, Osvaldo Felli, Daniel Grenón e Gabriel Quaino pelo apoio e estímulo para a realização do curso.

A todos meus companheiros de pós-graduação pelo convivio e amizade.

A Silvia del Carmen Imhoff pela confiança, apoio e amizade. 


\section{SUMÁRIO}

\section{Página}

RESUMO

SUMMARY

1 INTRODUÇÃO

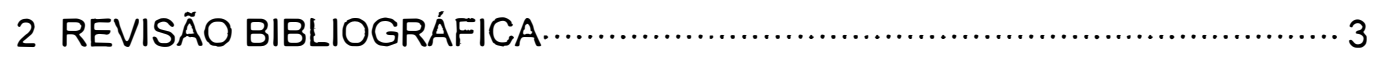

2.1 Modelos de infiltração …………......................................................

2.1.1 Modelo de Kostiakov (1932) …............................................... 4

2.1.2 Modelo de Horton (1940) …................................................. 5

2.1.3 Modelo de Green \& Ampt (1911) …........................................... 5

2.1.4 Modelo de Philip (1957) …...................................................

2.2 Metodologias para estimação dos parâmetros de infiltração …………... 9

2.2.1 Métodos de laboratório ……................................................. 9

2.2.2 Método da drenagem interna …............................................. 11

2.2.3 Infiltrômetros sob tensão ……................................................. 13

2.2.3.1 Aspectos teóricos da utilização de infiltrômetros de tensão …. 14

2.2.3.2 Método do Scotter et al. (1982) …...................................... 16

2.2.3.3 Método de Ankeny et al. (1991) ........................................... 17

2.2.3.4 Método de White et al. (1992) ….......................................... 18

2.2.3.5 Metodo de Warrick (1992) …............................................... 19 
3 MATERIAL E MÉTODOS

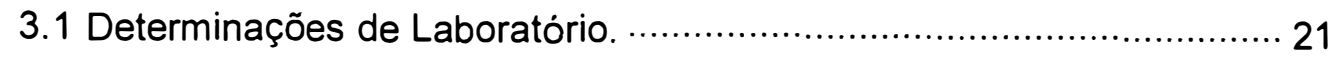

3.1.1 Curvas de retenção da água no solo. ………............................... 21

3.1.2 Condutividade hidráulica saturada e densidade do solo. ...............22

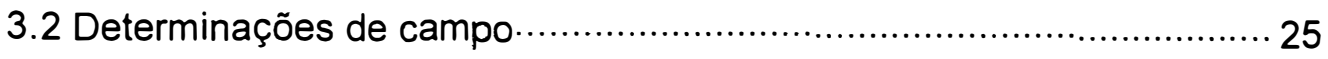

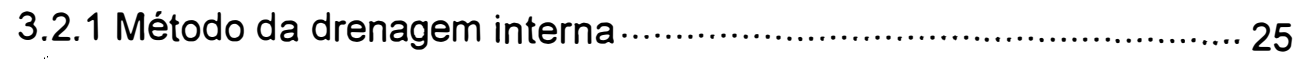

3.2.2 Método utilizando o infiltrômetro de tensão …………………......... 29

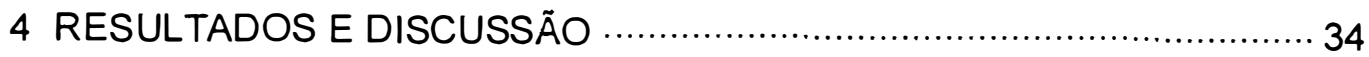

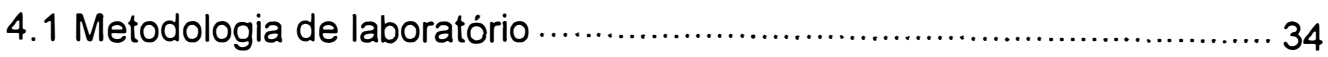

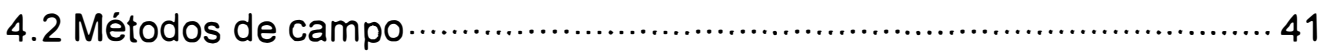

4.2.1 Método da drenagem interna …................................................ 41

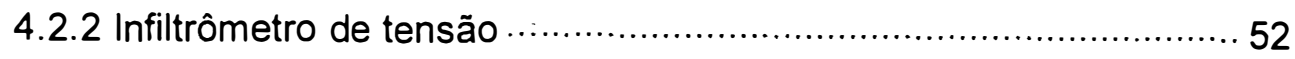

4.3 Comparação das metodologias utilizadas …….................................... 56

5 CONCLUSÕES

ANEXO

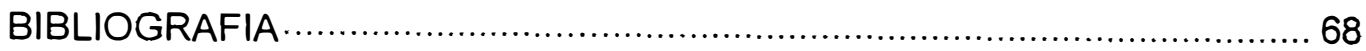

APÊNDICE 


\title{
METODOLOGIAS PARA A OBTENÇÃO DE PARÂMETROS UTILIZADOS EM MODELOS DE INFILTRAÇÃO DA ÁGUA NO SOLO
}

\author{
Autor: PABLO JAVIER GHIBRTO \\ Orientador: Prof. Dr. SÉRGIO OLIVEIRA MORAES
}

\section{RESUMO}

Os modelos de infiltração precisam de parâmetros que podem ser obtidos a partir de diferentes métodos experimentais ou analíticos utilizando distintas formas de cálculo. O objetivo do presente trabalho é apresentar os modelos de infiltração levando em consideração a problemática do fornecimento dos parâmetros por eles requeridos. O experimento consistiu na aplicação dos métodos do permeâmetro de carga constante (Youngs, 1991), da condutividade hidráulica a partir da curva de retenção de água no solo (van Genuchten, 1980); perfil instantâneo (Hillel et al., 1972), métodos da umidade e do fluxo (Libardi et al., 1980) e infiltrômetro de tensão (Scotter et al., 1982; Ankeny et al., 1991), para obtenção da condutividade hidráulica em função do conteúdo hídrico $(K(\theta))$, a sortividade $(S)$, infiltração acumulada $(I)$ e conteúdo hídrico de saturação. O experimento foi conduzido em Piracicaba (SP), Brasil, 22 $41^{\prime}$ ' de latitude sul e 47 $7^{\circ} 39^{\prime}$ de longitude oeste sob solo Latossolo Vermelho Amarelo de

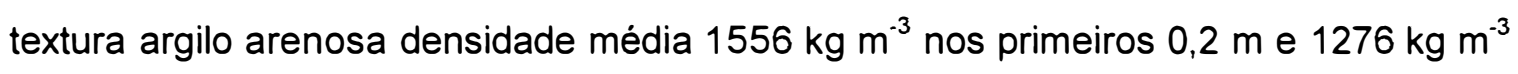
até um metro de profundidade. Os maiores valores de condutividade hidráulica saturada foram obtidos com o permeâmetro de carga constante possivelmente pelas amostras terem, atingido condições mais próximas à saturação. A faixa mais ampla de valores de $K(\theta)$ foi obtida pelo método de van Genuchten (1980). Pelo método da drenagem interna ajustou-se a equação $K=K_{0} \exp \gamma\left(\theta-\theta_{0}\right)$ que descreve a relação $K(\theta)$ apresentando dificuldades na estimativa da condutividade hidráulica próximo a saturação. O gradiente hidráulico foi crescente com 0 transcurso do tempo de redistribuição e em algumas profundidades se apresentou perto da unidade até aproximadamente 10 dias após iniciada a redistribuição. $O$ infiltrômetro de tensão mostrou-se útil em baixas tensões onde as outras metodologias foram mais 
problemáticas, mas necessita-se de mais pesquisas visando a padronização da metodologia de utilização e cálculo. Conclui-se que devido à simplicidade do instrumental e da infra-estrutura necessárias e à possibilidade de ampliação do número de repetições e assim contemplar-se a variabilidade espacial e temporal das propriedades hídricas do solo, o infiltrômetro de tensão mostrou-se uma ferramenta satisfatória para o levantamento dos parâmetros dos modelos de infiltração analisados. 


\title{
METHODOLOGIES TO DETERMINE PARAMETERS OF SOIL WATER INFILTRATION MODELS
}

\author{
Author: PABLO JAVIER GHIBRTO \\ Adviser: Prof. Dr. SÉRGIO OLIVEIRA MORAES
}

\section{SUMMARY}

The parameters of the models used to evaluate the water infiltration in soils can be determined by means of different experimental or analytical methods and different techniques of calculation. The objective of this work is to study the infiltration models by taking into account the supply of their pertinent parameters. The determination of the soil hydraulic conductivity as a function of soil-water content $(K(\theta))$, the sortivity $(S)$ and the accumulated soil water infiltration $(I)$ was accomplished by using the following methods: constant head permeameter method (Youngs, 1991); hydraulic conductivity from soil-water retention curve method (van Genuchten, 1980); instantaneous profile method (Hillel et al, 1972); soil-water content and flux methods (Libardi et al, 1980); and tension infiltrometer method (Scotter et al, 1982; Ankeny et al, 1991). The experiment was carried out in Piracicaba (SP), Brazil $\left(22^{\circ} 41^{\prime} S\right.$ and $47^{\circ} 39^{\prime} \mathrm{W}$ ) in a sandy clay Red-Yellow Latosol with soil bulk density mean values of $1556 \mathrm{~kg} \mathrm{~m}^{-3}$ in the $0,2 \mathrm{~m}$ superficial layer and of $1276 \mathrm{~kg} \mathrm{~m}^{-3}$, in the layer from 0,2 to $1,0 \mathrm{~m}$. The higher saturated hydraulic conductivity values were achieved with the constant head permeameter method, probably because, in this case, the samples have reached, in relation to the other methods, conditions nearer the saturation. The higher range of $K(\theta)$ values were achieved by van Genuchten (1980) method. In the instantaneous profile method, the hydraulic gradient increased with the redistribution time, being near the unit till, approximately, 10 days of redistribution. The tension infiltrometer method was useful at low tensions where the other methodologies were less adequate, but more research are needed in order to standardize its procedure of use and calculation; anyway, it was a satisfactory method to determine the parameters of the used soil water infiltration models. 


\section{INTRODUÇÃO}

A água apresenta um comportamento dinâmico no solo. Seu movimento pode ser omnidirecional, e inclui os processos de infiltração, redistribuição, drenagem e evaporação.

A infiltração é definida como a penetração da água nos poros do solo e constitui um processo "chave" no ciclo hidrológico. A interface ar-solo pode separar a água que atinge a superficie em duas partes, uma que penetra, fica armazenada, é absorvida pelas raizes ou drena em profundidade; e outra que pode escoar superficialmente e causar erosão. Outros importantes processos como movimentação de solutos estão também ligados à infiltração.

Ha muitas pesquisas sobre o assunto e entre elas, o desenvolvimento de equações que tentam descrever o fenômeno matematicamente. Assim, podem-se encontrar na literatura desde as que são totalmente empíricas até as que têm um grande desenvolvimento analítico e cada uma tem vantagens e desvantagens de acordo com os pressupostos assumidos e o nível de precisão requerido pelo usuário.

A natureza heterogênea do solo por si só dificulta a descrição matemática da movimentação da água. Fenômenos de histerese, encrostamento superficial, estratifição do solo e presença de rachaduras são exemplos da complexidade do processo que levam ao insucesso quando são aplicadas teorias desenvolvidas para solos homogêneos.

Uma vez definido o modelo (ou modelos de interesse) que contemple a precisão desejada para o conhecimento do fenômeno aliada e seja adequado à complexidade que determinado solo exibe, o passo seguinte é definir os métodos de obtenção dos parâmetros que intervém no modelo ou nos modelos sob estudo. 
Os métodos de obtenção dos parâmetros podem ser indiretos, quando forem determinados de forma analitica ou empirica a partir de outras propriedades do solo que se relacionam com o parâmetro de interesse, ou obtidos diretamente de medidas em laboratório e "in situ". Os fatores que condicionam o uso do modelo, além dos já mencionados, estão também relacionados aos aspectos financeiros e de tempo disponivel para as análises laboratoriais ou de campo, conforme o caso.

Face ao exposto, o objetivo do presente trabalho é apresentar os modelos de infiltração levando em consideração a problemática do fornecimento dos parâmetros por eles requeridos. 


\section{REVISÃO BIBLIOGRÁFICA}

$\mathrm{Na}$ primeira parte desta revisão são apresentados os modelos de infiltração, dando-se ênfase aos parâmetros que requerem e na segunda parte, apresentam-se as metodologias para obter tais parâmetros. São discutidos os métodos da drenagem interna, infiltrômetro sob tensão e obtenção da condutividade hidráulica a partir da curva de retenção obtida em laboratório. As comparações entre as técnicas existentes facilitam a identificação de prós e contras de cada método e racionalizam sua aplicabilidade (Marion et al., 1994). Deve-se deixar claro que no trabalho é utilizada a mesma simbologia que a apresentada na literatura.

\subsection{Modelos de infiltração}

Os modelos matemáticos que caracterizam a infiltração envolvem simplificações que permitem expressar de forma algébrica a taxa de infiltração ou a infiltração acumulada em relação a alguns parâmetros físicos do solo e podem ser empiricos, semianaliticos ou analiticos (Childs, 1969).

Iwata \& Tabuchi (1988) classificaram em três grupos os modelos de infiltração de acordo com o movimento da água no solo. Os que utilizam taxa de entrada de água determinada empiricamente: Kostiakov (1932) e Horton (1940); os baseados na equação de Darcy-Buckingham (Libardi, 1995) que utilizam a taxa de infiltração a umidade inicial e o potencial mátrico na frente de molhamento: Green \& Ampt (1911); e os baseados na equação de difusão onde a infiltração relaciona-se a gradientes de potencial da água devidos a diferentes conteúdos hidricos: Philip (1957a) e Philip (1957b). Além dos modelos anteriormente citados, outras equações foram desenvolvidas (Hopmans et al.,1997) e merecem destaque as devidas a, Parlange et al. (1982) e Swartzendruber (1987). 
Antes de passar-se ao estudo dos modelos, são colocadas algumas observações gerais sobre as dificuldades na sua utilização. O comportamento dos modelos aplicados a diferentes condições experimentais e de solo é discutido na literatura por vários autores (Swartzendruber, 1974; Gurovich, 1977; Wells et al., 1986; Rawls \& Brakensiek, 1986; Chaves et al., 1993; Mwendera \& Feyen, 1993; Mbagwu, 1995). Young (1995) apresenta uma revisão histórica do desenvolvimento da teoria da infiltração incluindo as soluções clássicas baseadas na equação de Richards para fluxo não saturado. Discute também os problemas dos pressupostos no desenvolvimento teórico e os fatores que complicam tal descrição, dentre eles destacam-se: o efeito do ar aprisionado, a heterogeneidade, os fenômenos de expansão-contração, o fluxo preferencial por macroporos e a inestabilidade do solo, os desvios da lei de Darcy e os efeitos de temperatura e histerese.

Talvez a maior dificuldade na aplicabilidade dos métodos é que as equações foram desenvolvidas para solos homogêneos e que permanecem homogêneos durante o processo (Libardi, 1995) e desta forma, muitos erros são produzidos ao violar os supostos implícitos em cada equação além dos causados pela falta de certeza ao medir os parâmetros requeridos (Clausnitzer et al., 1998).

O desenvolvimento teórico que representa 0 processo não acompanhou 0 avanço das metodologias de cálculo e das técnicas computacionais (van Genuchten, 1980). Outro problema reside na determinação das propriedades físicas do solo devido à sua heterogeneidade espacial sendo requeridas numerosas medidas para descrever adequadamente as condições do campo (Skaggs \& Khaleel, 1982; Chow et al, 1988).

Em seguida são apresentados modelos clássicos de infiltração com seus pressupostos e parâmetros requeridos seguindo uma ordem que vai dos puramente empíricos até os analíticos. De fato, ao longo do tempo houve modificações que produziram melhorias ou adaptações a situações particulares, mas basicamente todos requerem os mesmos parâmetros. 


\subsubsection{Modelo de Kostiakov (1932)}

Uma das mais simples equações de infiltração utilizadas em sistemas de irrigação foi proposta por Kostiakov (1932),

$$
i(t)=a t^{-\beta}
$$

onde $i(t)$ é a capacidade de infiltração, $t$ é o tempo depois que a infiltração começa, e $a$ e $\beta$ são parâmetros que dependem do solo e das condições iniciais. Estes parâmetros não têm interpretação física e podem ser obtidos a partir do ajuste da função apresentada aos dados experimentais.

\subsubsection{Modelo de Horton (1940)}

Horton (1940) observou que no princípio do processo a infiltração ocorre em uma taxa $i_{O}$ que decresce exponencialmente até atingir uma taxa constante $i_{C}$ :

$$
i(t)=i_{c}+\left(i_{0}-i_{c}\right) e^{-\beta t}
$$

onde $\beta$ é o decaimento constante com dimensões $\left[\mathrm{T}^{-1}\right]$. A determinação dos três parâmetros $\left(i_{O}, i_{\mathcal{C}}, \beta\right)$ pode ser feita a partir de observações separadas de valores simultâneos de $i$ e $t$. Comentários sobre a aplicabilidade da equação de Horton podem ser vistos em Libardi (1995).

\subsubsection{Modelo de Green \& Ampt (1911)}

Um enfoque alternativo que tem uma solução analítica exata é dado pelo modelo de Green \& Ampt (1911). Propõe que dado um solo com uma quantidade $h_{O}$ de água na superfície, a infiltração ocorre formando um frente de molhamento que divide o conteúdo hídrico do solo em uma zona saturada e imediatamente abaixo da zona saturada o conteúdo hídrico inicial $\left(\theta_{n}\right)$. A partir do começo da infiltração a frente de molhamento percorre no tempo $t$ uma profundidade $L$. 
Se $\circ$ solo encontra-se inicialmente com uma umidade uniforme, $\theta_{\mathrm{n}}$, até a profundidade $L$, o conteúdo de água vai aumentar de $\theta_{\mathrm{n}}$ até $\eta$ (porosidade) a medida que a frente de molhamento avança no solo. $O$ incremento do volume de água armazenada resultante da infiltração é $L\left(\eta-\theta_{n}\right)$ e por definição esta quantidade é igual a $I$, infiltração de água acumulada até a profundidade do solo $L$, isto é,

$$
I(t)=L\left(\eta-\theta_{n}\right)=L \Delta \theta
$$

Utilizando a equação de Darcy-Buckingham (Libardi, 1995), Green \& Ampt deduziram que a infiltração acumulada é dada por:

$$
\mathrm{I}(\mathrm{t})=\mathrm{Kt}+\psi_{\mathrm{f}} \Delta \theta \ln \left[1+\frac{\mathrm{I}(\mathrm{t})}{\psi_{\mathrm{f}} \Delta \theta}\right]
$$

onde $\psi_{\mathrm{f}}$ é a tensão na frente de molhamento.

A eq. 4 tem $\circ$ problema que $I(t)$ não pode ser explicitado. Pode-se resolver pelo método de substituições sucessivas, isto é, dados $K, t, \psi_{\mathrm{f}}$ e $\Delta \theta$, um valor trivial $I$ é substituindo no segundo termo da equação (um valor trivial é $I=K t$ ), e um novo valor de $I$ calculado no termo da esquerda, o procedimento repete-se até que $\circ$ valor $I$ converge a um valor constante.

Ao final o valor da infiltração acumulada é substituido em (2) para determinar a correspondente taxa de infiltração $i(t)$.

$$
\mathrm{i}(\mathrm{t})=\mathrm{K}\left[\frac{\psi_{\mathrm{f}} \Delta \theta}{\mathrm{I}(\mathrm{t})}+1\right]
$$

A aplicação do modelo de Green \& Ampt (1911) requer a estimação da condutividade hidráulica $K$, a porosidade do solo $\eta$, e a tensão na frente de molhamento sendo para este último parâmetro propostas diversas formas de cálculo na literatura. 
A variação da tensão com a umidade volumétrica, $\theta$, e a condutividade hidráulica foi estudada por Brooks \& Corey (1964). Concluíram, depois de testar no laboratório muitos solos, que $\psi_{\mathrm{f}}$ pode-se expressar como uma função logaritmica da saturação efetiva $S_{e}$, definida como $S_{e}=\left(\theta-\theta_{r}\right) /\left(\eta-\theta_{r}\right)$ sendo $\theta_{r}$ a umidade volumétrica residual e a diferença $\eta$ - $\theta_{r}$ a porosidade efetiva $\theta_{\mathbf{e}}$. Brakensiek et al. (1981) apresentam um método para estimar os parâmetros da equação de Green \& Ampt utilizando a equação de Brooks \& Corey. Rawls et al. (1983) citado por Chow et al. (1988) com o uso da equação de Brooks-Corey analisaram aproximadamente 5000 solos nos Estados Unidos e determinaram valores médios dos parâmetros do modelo de Green \& Ampt (1911) ( $\eta, \theta_{\mathrm{e}}, \psi_{\mathrm{f}}$ e $K$ ) para diferentes classes de solo e observaram que em texturas argilosas a tensão na frente de molhamento é maior e a condutividade hidráulica menor em comparação aos de classes texturais mais arenosas.

A tensão na frente de molhamento pode ser determinada também, a partir do conhecimento da condutividade hidráulica como uma função da tensão, $\psi_{\mathrm{f}}=\int \mathrm{K}(\psi) \mathrm{d} \psi$ (Mein \& Larson, 1973) ou do comprimento macroscópico capilar (macroscopic capillary lenght), e uma constante, $b$, utilizando a seguinte expressão $\left|\psi_{\mathrm{f}}\right|=\lambda d(2 b)$ (White \& Sully, 1987). Kutilek \& Nielsen (1994) apresentam outras formas de se estimar $\psi_{f}$.

Skaggs \& Khaleel (1982) citam que a flexibilidade do modelo de Green \& Ampt para descrever a infiltração sob diferentes condições iniciais e do perfil do solo, fez dele um método atrativo para aplicações de campo. O fato de que os parâmetros da equação tenham significado físico e possam ser computados a partir das propriedades do solo são vantagens adicionais.

\subsubsection{Modelo de Philip (1957)}

Philip (1957a) resolveu a equação de Richards assumindo que a condutividade hidráulica e a difusividade variam com a umidade volumétrica $(\theta)$. Para tal, Phillip utilizou a transformação de Boltzmann $B(\theta)=z \times t^{-1 / 2}$ e após de manipulações matemáticas que podem ser encontradas em Libardi (1995) obteve uma solução para a infiltração acumulada $I(t)$ na direção vertical: 


$$
I(t)=S t^{1 / 2}+F t
$$

Que por diferenciação fornece:

$$
i(t)=\frac{1}{2} \mathrm{St}^{-1 / 2}+\mathrm{F}
$$

onde $S$, é um parâmetro do solo chamado sortividade (Philip, 1957b) que indica a capacidade de um solo homogêneo de absorver água em relação a sua umidade inicial, enquanto que a constante $F$ está relacionada com a contribuição da gravidade ao movimento da água. As constantes $S$ e $F$ podem ser calculadas a partir de equações teóricas ou aproximadas a partir de medições da infiltração em diferentes tempos.

As equações satisfazem as condições que para tempos pequenos a taxa de infiltração é grande, e para tempos mais longos, tende a um valor constante, $F$, que no entanto, não é a condutividade hidráulica saturada na superficie do solo. As equações são válidas somente para os primeiros estágios da infiltração, isto é, para $t$ relativamente pequenos (Kutilek \& Nielsen 1994; Libardi, 1995).

O Quadro 1 apresenta um resumo dos parâmetro requeridos pelos modelos de infiltração apresentados anteriormente.

Quadro 1. Parâmetros necessários para alguns dos modelos de infiltração da água no solo (Gurovich et al., 1977)

\begin{tabular}{llllllllllll}
\hline Modelo & $(1)$ & (2) & $(3)$ & $(4)$ & (5) & $(6)$ & (7) & (8) & (9) & (10) & (11) \\
\hline Kostiakov & $\checkmark$ & & & & & & & & & \\
Horton & $\checkmark$ & & & & & & & & & \\
Green\&Ampt & $\checkmark$ & $\checkmark$ & $\checkmark$ & $\checkmark$ & $\checkmark$ & $\checkmark$ & $\checkmark$ & $\checkmark$ & $\checkmark$ & & $\checkmark$ \\
Philip & $\checkmark$ & & $\checkmark$ & & $\checkmark$ & & & & & $\checkmark$ & \\
\hline
\end{tabular}

(1) Infiltração acumulada em função do tempo

(2) Porosidade do solo por estrato 
(3) Conteúdo hídrico inicial por estrato no perfil de infiltração

(4) Profundidade do perfil do solo

(5) Espessura de cada estrato

(6) Curva de retenção hídrica por estrato

(7) Condutividade hidráulica de saturação

(8) Profundidade do avanço da frente de molhamento

(9) Condutividade hidráulica em função do conteúdo hídrico do solo

(10) Sortividade

(11) Potencial mátrico na frente de molhamento

A seguir apresentam-se alguns métodos para a obtenção dos parâmetros apresentados no Quadro 1, sendo discutidas também formas de cálculo, vantagens e desvantagens de cada um deles.

\subsection{Metodologias para estimação dos parâmetros de infiltração}

\subsubsection{Métodos de laboratório}

As metodologias para determinar a condutividade hidráulica são em geral custosas em tempo e dinheiro e muitas vezes laboriosas e apesar do esforço, a precisão dos resultados é em muitas ocasiones baixa (Dirksen, 1991).

A condutividade hidráulica pode ser derivada da curva de retenção hídrica. Uma das vantagens desse método é a possibilidade de obter valores de condutividade em uma ampla faixa de conteúdos hidricos na qual a instrumentação utilizada "in situ" não poderia medir eficientemente. Aliás, podem ser utilizados na caracterização de grandes áreas e ajudar na comparação de diferentes solos (Marion et al., 1994).

Embora a curva de retenção tenha a capacidade de refletir as propriedades hidráulicas através da geometria porosa do solo, os modelos desenvolvidos para descrever as propriedades em meios porosos homogêneos com distribuição dos diâmetros dos poros de tipo unimodal, não podem levar em conta o impacto dos poros estruturais na retenção da água e na condutividade hidráulica perto da saturação (Jarvis \& Messing, 1995) em conseqüência, foram propostos modelos de domínios múltiplos (Othmer et al, 1991). Não obstante, poucos estudos (Clothier \& Smettem, 
1990) têm obtido medições detalhadas da condutividade hidráulica próxima a saturação que poderiam servir como entrada em tais modelos devido às dificuldades experimentais envolvidas. O desenvolvimento de técnicas experimentais novas e melhoradas para pesquisar a natureza de $K(\theta)$ perto da saturação devem portanto dirigir a aplicação dos modelos de dois ou múltiplos dominios de propriedades hidráulicas recentemente desenvolvidos. A conseqüência seria que os efeitos da estrutura do solo no fluxo da água e no transporte de solutos poderiam ser melhor preditos (Jarvis \& Messing, 1995).

Baseado no trabalho de Burdine (1953) (citado por Mualem, 1976), Mualem (1976) derivou um modelo de predição da condutividade hidráulica utilizando a curva de retenção hidrica:

$$
K_{r}=\Theta^{1 / 2}\left[\frac{\int_{0}^{\Theta} \frac{1}{\psi(x)} d x}{\int_{0}^{1} \frac{1}{\psi(x)} d x}\right]^{-2}
$$

onde $K_{r}=K / K_{\text {sat }}$ é a condutividade hidráulica relativa; $\psi$ o potencial matricial e $\Theta=\left(\theta-\theta_{r}\right) /\left(\theta_{s}-\theta_{r}\right)$ representa a saturação efetiva sendo $\theta_{r}$ a umidade residual e $\theta_{s}$ a umidade de saturação. O método precisa de uma equação que se ajuste da melhor maneira possivel à curva de retenção de água no solo. Muitos trabalhos apresentam curvas de ajuste, por exemplo, van Genuchten (1980), propôs que:

$$
\Theta=\left[\frac{1}{1+(\alpha \psi)^{n}}\right]^{m}
$$

onde $\alpha, n$, e m são parâmetros caracteristicos de cada solo pelo ajuste de dados experimentais à função proposta, Kutilek \& Nielsen (1994) apresentam uma revisão do assunto. A vantagem desta solução é ser uma função continua e derivável.

Com a simplificação $m=1-1 / n$ (Mualem, 1976), van Genuchten (1980) combinou a eq. 8 com a eq. 9 obtendo: 


$$
K_{r}=\Theta^{\ell}\left[1-\left(1-\Theta^{1 / m}\right)^{m}\right]^{2}
$$

sendo $l$ um parâmetro empirico que tem um valor 0,5 para a maioria dos solos.

No cálculo de $K(\theta)$ é freqüente utilizar-se a condutividade hidráulica saturada medida em laboratório o que nem sempre é uma boa escolha, pois normalmente o desvio padrão é grande (Dirksen, 1991). Embora o autor não explicite a ordem de grandeza do desvio, Warrick \& Nielsen (1980) citam coeficientes de variação da condutividade hidráulica saturada superiores ao $100 \%$ e classificam ao parâmetro como de alta variação.

\subsubsection{Método da drenagem interna}

Hillel et al. (1972) desenvolveu o método do perfil instantâneo que permite o cálculo da função $K(\theta)$ a partir da evolução da umidade no tempo num processo de drenagem interna no qual a evaporação é anulada. São assumidos fluxo unidimensional, condições isotérmicas, ausência de histerese e da influência do lençol freático, permitindo a utilização da equação de Richards para o cálculo de:

$$
\left.K(\theta)\right|_{z}=\frac{\int_{0}^{z} \frac{\partial \theta}{\partial t} d z}{\left.\frac{\partial \psi_{t}}{\partial z}\right|_{z}}
$$

O procedimento foi amplamente utilizado nas décadas seguintes e segundo Reichardt et al. (1998) tem a desvantagem do uso das diferenças finitas e valores médios de conteúdo hidrico volumétrico em incrementos bastante longos de tempo. Deve-se deixar claro que as diferenças finitas não são inerentes ao método e que os incrementos de tempo nos quais se mede o conteúdo hídrico volumétrico dependem da variação da umidade no processo de redistribuição não sendo estes necessariamente motivos reais de crítica à metodologia.

Ainda, a principal desvantagem do método é a faixa de $\theta$ e de $\psi$ na qual pode ser determinado $\mathrm{K}(\theta)$ (Dirksen, 1991). Na faixa úmida a limitação se produz pelo grau 
de saturação atingido com a inundação inicial na superficie, que em geral não é maior que 90 \% do volume poroso (Chong et al., 1981; Dirksen, 1991; Arya et al., 1998). O ar tende a ficar aprisionado na frente de molhamento afetando o comportamento do fluxo da água. Na faixa seca, o limite é dado pelas características do solo em estudo sendo difícil depois de vários dias de drenagem detectar diferenças de umidade ficando os valores de potencial matricial entorno de $-20 \mathrm{kPa}$ (Dirksen, 1991).

Em experimentos de drenagem é maior a probabilidade de cometer erros em condições mais secas e esses erros são logo transmitidos no cálculo da condutividade hidráulica (Dirksen, 1991; Bacchi \& Reichardt, 1993). Por outro lado, os erros cometidos em tensões altas são menos importantes que em pequenas porque as últimas têm maior influência na infiltração (Ahuja et al., 1988) e fluxo pelos macroporos.

O problema da variabilidade da umidade no espaço e no tempo e sua influência no estudo de $K(\theta)$ precisa de mais estudos. Falleiros et al. (1998) apresentaram que pequenas variações na determinação da umidade produzem fortes influencias no $K(\theta)$ que poderiam fazer inviável a metodologia, deve ser esclarecido que a conclução foi feita numa determinada condição experimental e portanto não pode ser generalizada.

Davidson (1969), apresentou que no processo de drenagem num perfil uniforme de solo o gradiente é unitário na maior parte do processo. Isto foi de grande interesse para profissionais da área porque somente medindo a umidade volumétrica no processo de redistribuição podia-se obter a condutividade hidráulica. Várias metodologias de campo incorporaram este suposto (Libardi et al., 1980; Sisson, et al. 1980; Chong et al. 1981), sendo sua validade freqüentemente questionada (Ahuja et al. 1988, Reichardt, 1993; Bacchi \& Reichardt, 1993). Embora possa mostrar sua utilidade para condições onde essas metodologias foram desenvolvidas, como por exemplo solos homogêneos.

No método da umidade, Libardi et al. (1980) considerando $\partial \psi_{\mathrm{l}} / \partial z=1$ e substituindo a equação $K=K_{O} e^{\left.\gamma \theta-\theta_{0}\right)}$ na eq. 11 resolveram a integral resultando: 


$$
\theta_{0}-\theta=\frac{1}{\gamma} \ln \mathrm{t}+\frac{1}{\gamma} \ln \frac{\gamma \mathrm{K}_{0}}{\mathrm{az}}
$$

que indica que a umidade do solo na profundidade $z$ é uma função linear de $\ln t$, pois $\gamma K_{\mathrm{o}} l a z$ é uma constante. Libardi et al. (1980) mostraram que a umidade média pode ser descrita por:

$$
\bar{\theta}(z, t)=a(z) \theta(z, t)+b(z)
$$

O método do fluxo, Libardi et al. (1980), possui as mesmas condições acima. Substituindo $K=K_{O} e^{\gamma(\theta-\theta 0)}$ em $[\partial \theta / \partial t] z=K(\theta)\left[\partial \psi_{1} / \partial z\right]$ e considerando $\partial \psi_{1} / \partial z=1$ obtiveram:

$$
\ln \left|\mathrm{z} \frac{\mathrm{d} \ddot{\theta}}{\mathrm{dt}}\right|=\ln \mathrm{K}_{0}-\gamma\left(\theta_{0}-\theta\right)
$$

que indica que o logaritmo do fluxo de água é uma função linear de $\theta$. A constante $y$ é obtida em ambos casos a partir de regressões lineares.

Os principais argumentos contra a utilização do gradiente hidráulico unitário são, primeiro, que parece ser válida apenas para efeito prático, mas não o sendo teoricamente (Reichardt, 1993; Bacchi \& Reichardt, 1993); e segundo, que os gradientes hidráulicos são influenciados geralmente, pela natureza e complexidade do solo variando com o tempo e profundidade (Ahuja et al., 1988; Chong et al., 1981).

\subsubsection{Infiltrômetros de tensão}

Os infiltrômetros de tensão vêm sendo utilizados no estudo do efeito de diferentes práticas de manejo agricola através de parâmetros que refletem as alterações da estrutura porosa do solo nas propriedades hidráulicas (Whyte \& Perroux, 1989; Ankeny et al., 1990; Logsdon et al., 1993). Também são úteis na quantificação do fluxo preferencial pelos macroporos (Watson \& Luxmoore, 1986; Wilson \& Luxmoore, 1988; Dunn \& Phillips, 1991) fato que se encontra ligado ao transporte de solutos. 
Comparado com os métodos anteriores, a metodologia é simples, produz menores perturbações no local de medição, um operário pode fazer as medições, e permite obter propriedades hidráulicas como condutividade hidráulica sob diferentes tensões, sortividade, e diâmetro do poro caraterístico, entre outras.

Existem diferentes metodologias de cálculo e de utilização do instrumento para obter essas informações. Elas diferem no tipo e número de infiltrômetros a serem utilizados, tipo de dados requeridos e limitações e problemas encontrados no uso (Logdson \& Jaynes, 1993). Por outro lado, cada método tem supostos teóricos, e sua validade precisa ser considerada na decisão de qual utilizar e somado a que os solos podem diferir grandemente em suas propriedades, não é possivel decidir a priori qual se adapta melhor numa determinada situação (Cook \& Broeren, 1994).

Mas como bem fala White et al. (1992): "Os permeâmetros de tensão não são a panacea da fisica de solos"; às principais limitações estão associadas às simplificações dos pressupostos utilizados para extrair as propriedades do solo. Podendo-se citar como desfavoráveis o pressuposto de homogeneidade do solo, a presença de fenômenos de expansão contração, o tempo para atingir o equilibiro pode ser muito longo, a interferência do material de contato entre o solo e o aparelho, presença de condições hidrófobas e alterações na viscosidade da água no momento de leitura.

A seguir são apresentados alguns aspectos teóricos básicos do infiltrômetro de tensão e das principais metodologias de cálculo encontradas na bibliografia.

\subsubsection{Aspectos teóricos da utilização de infiltrômetros de tensão}

Gardner (1958) apresentou uma solução analitica para obter K( $(\psi)$ expressa pela equação:

$$
\mathrm{K}(\psi)=\mathrm{K}_{0} \mathrm{e}^{\alpha \psi}
$$

onde $K_{O}$ é a condutividade hidráulica saturada, $\psi$ o potencial matricial e $\alpha$ uma constante. $O$ parâmetro $\alpha$ pode ser aproximado por $\alpha=\lambda_{c}^{-1}$ sendo $\lambda_{c} \circ$ comprimento 
macroscópico capilar (capillary macroscopic length), (White \& Sully; 1987). O comprimento macroscópico capilar foi definido como:

$$
\lambda_{c}=\left(K_{0}-K_{n}\right)^{-1} \int_{\psi_{n}}^{\psi_{0}} K(\psi) d \psi
$$

White \& Sully (1987) rescreveram a eq. 16 em termos de propriedades do solo:

$$
\lambda_{c}=\frac{b S^{2}}{\Delta K \Delta \theta}
$$

onde $b$ é um parâmetro relacionado à difusividade da água no solo e seu valor pode ser encontrado entre $0,5 \leq b \leq \pi / 4$. Um valor típico de $b$ é 0,55 . Define-se que $\Delta K=K\left(\psi_{0}\right)-K\left(\psi_{n}\right)$ com $K\left(\psi_{n}\right)$ e $K\left(\psi_{0}\right)$ sendo as condutividades hidráulicas no inicio e fim da infiltração respetivamente. É razoável assumir-se que $\Delta K=K\left(\psi_{0}\right)$ pois $K\left(\psi_{0}\right) \gg K_{(}\left(\psi_{n}\right)$ levando em conta que no inicio da infiltração o solo encontra-se com baixa umidade. Uma utilidade adicional de $\lambda_{c}$ é sua relação com o tamanho médio do poro, $\lambda_{m}$ :

$$
\lambda_{\mathrm{m}}=\frac{\sigma}{\rho g \lambda_{\mathrm{c}}}
$$

onde $\sigma$ é a tensão superficial da água, $\rho$ a densidade da água no solo e $g$ a aceleração da gravidade.

Os seguintes métodos de cálculo para utilização do infiltrômetro de tensão são baseados na aproximação feita por Wooding (1968) que analisa a infiltração em equilíbrio dinâmico a partir de uma fonte circular de aplicação de água, assumindo como válida a equação de Darcy e que o solo é uniforme com uma umidade inicial, $\theta_{n}$, tal que $\psi_{\mathrm{n}} \rightarrow-\infty$. Wooding (1968) linearizou a função exponencial proposta por Gardner (1958):

$$
\frac{\mathrm{Q}_{\infty}}{\pi \mathrm{r}^{2}}=\Delta \mathrm{K}\left[1+\frac{4 \lambda_{\mathrm{c}}}{\pi \mathrm{r}}\right]
$$


Normalmente considera-se que $K_{O}>>K_{n}$ e portanto, $\Delta K=K\left(\psi_{0}\right)$. A mesma equação pode ser escrita como:

$$
\mathrm{q}_{\infty}=\pi \mathrm{r}^{2} \mathrm{~K}\left(\psi_{0}\right)+4 \phi\left(\psi_{0}\right)
$$

onde $\phi\left(\psi_{0}\right)$ é o potencial de fluxo mátrico (Raats \& Gardner, 1971) e representada por:

$$
\phi\left(\psi_{0}\right)=\int_{\psi_{n}}^{\psi_{0}} \mathrm{~K}(\psi) \mathrm{d} \psi=\int_{\theta_{n}}^{\theta_{0}} \mathrm{D}(\theta) \mathrm{d} \theta
$$

$\mathrm{Na}$ eq. 20 o termo da esquerda tem dimensão de fluxo, o primeiro termo da direita representa a contribuição da gravidade ao fluxo e o segundo a influência da capilaridade do solo e geometria da fonte.

Para intervalos de tempo curtos com um potencial $\psi_{0}$ na base do infiltrômetro existe um tempo, $t_{c}$, onde o fluxo capilar é o processo dominante, e a infiltração acumulada I(t) é dada pela seguinte relação (Philip, 1957a):

$$
\mathrm{I}_{0}=\mathrm{S}_{0} \mathrm{t}^{-1 / 2}
$$

onde $S_{0}$ representa a sortividade e pode ser calculada a partir do coeficiente angular da reta tangente à curva $\mathrm{I}$ vs. $\mathrm{t}^{1 / 2}$.

Philip (1969) definiu também o "tempo geométrico", $t_{\text {geom }}$, que é o tempo no qual a geometria do sistema domina o fluxo e o "tempo gravimétrico", $t_{\text {grav }}$ que representa fisicamente o tempo no qual o efeito da gravidade se iguala ao efeito da capilaridade, $\mathrm{t}_{\mathrm{c}}$. Podem ser calculados pelas equações:

$$
\begin{gathered}
t_{\text {geom }}=\left(\frac{\mathrm{r} \Delta \theta}{\mathrm{S}}\right)^{2} \\
\mathrm{t}_{\text {grav }}=\left(\frac{\mathrm{S}}{\mathrm{K}}\right)^{2}
\end{gathered}
$$




\subsubsection{Método do Scotter et al. (1982)}

Considerando que $S$ e especialmente $K$ são muito sensiveis as perturbações no solo e à variabilidade espacial, Scotter et al. (1982) sugerem a utilização de dois permeâmetros de raios diferentes, $r_{1}$ e $r_{2}$ para obter os fluxos estacionários $q_{1}$ e $q_{2}$ em uma tensão determinada (Anexo 1). A partir desses dados é possivel calcular $K\left(\psi_{0}\right)$ e S utilizando as seguintes expressões:

$$
\begin{gathered}
K=\frac{\left(q_{1} r_{1}-q_{2} r_{2}\right)}{r_{1}-r_{2}} \\
S=\left[\frac{\pi r_{1} r_{2} \Delta \theta\left(q_{1}-q_{2}\right)}{2\left(r_{1}-r_{2}\right)}\right]^{1 / 2}
\end{gathered}
$$

O trabalho cita também que para obter resultados razoáveis $r_{1}>2 r_{2} e$

$$
\begin{gathered}
C_{k}=\left(q_{1} r_{1}-q_{2} r_{2}\right) / q_{1} r_{1}>0,3 \\
C_{\phi}=\left(q_{2}-q_{1}\right) / q_{2}>0,3
\end{gathered}
$$

sendo $C_{k}, C_{\phi}$ parâmetros adimensionais. Smettem \& Clothier (1989) propõem a utilização de mais de dois raios e de uma regressão linear $\mathrm{q}_{\infty}$ vs. 1/r para obter $S$ e $K$ a partir da eq. 20. Desta maneira evitam-se as dificuldades de medir a sortividade em periodos de tempo muito curtos.

Logsdon \& Jaynes (1993) obtiveram resultados absurdos como valores de condutividade hidráulica negativos repetidas vezes utilizando o método de Smettem \& Clothier (1989) e citam que assumir uniformidade na sortividade com infiltrômetros de diferentes raios não é válido. Também, o método requer medições em diferentes locais e é muito sensivel às variações espaciais nas propriedades hidricas.

As umidades inicial, $\theta_{n}$, e final, $\theta_{0}$, variam com 0 tamanho da base do infiltrômetro (Logdson, 1993) sendo outro fator que complica os cálculos. Smettem \& 
Clothier (1989) utilizaram a curva de retenção para obter as umidades finais, mas interpolar umidades em tensões muito baixas é dificil (Bouma, 1991).

\subsubsection{Método de Ankeny et al. (1991)}

Com os dados de fluxo estacionário em dois potenciais diferentes e assumindo uma relação constante entre $\mathrm{K}$ e $\phi$ podem se obter as condutividades hidráulicas nas tensões utilizadas na medição (Anexo 1). Na prática, Ankeny et al. (1991) mediram o fluxo estacionário em quatro potenciais incluindo $\psi_{0}=0$ e calcularam $\mathrm{K}$ para diferentes pares de tensões. Uma das vantagens do método é que poderiam ser feitas medições a diferentes tensões no mesmo local, reduzindo os problemas causados pela variabilidade espacial do solo (Logdson \& Jaynes, 1993). Ankeny (1991) argumenta também que evita-se o problema de ter que medir a umidade volumétrica final na tensão de medida, $\theta\left(\psi_{0}\right)$, mas para calcular $S$ precisa-se de $\Delta \theta=$ $\left(\theta_{0}-\theta_{n}\right)$ (ver eq. 26)com o qual o problema não é totalmente resolvido (Cook \& Broeren, 1994).

Outras dificuldades do método são a determinação de quando o fluxo estacionário é atingido, e os problemas de histerese causados ao fazer medidas consecutivas no mesmo local começando das tensões mais baixas (Cook e Broeren, 1994). O problema da histerese poderia ser resolvido fazendo medições em diferentes locais com o conseqüente aumento da variabilidade na medição.

\subsubsection{Método de White et al. (1992)}

O método utiliza a sortividade $S_{1}$ e $S_{2}$ medida em duas tensões diferentes $\psi_{0,1}$ $\psi_{0,2}$ para obter $K$ da forma seguinte:

$$
\mathrm{K}\left(\begin{array}{c}
- \\
\psi
\end{array}\right)=\frac{\overline{\mathrm{S}} \Delta \mathrm{S}}{\Delta \bar{\theta} \Delta \psi_{0}}-\left(\frac{\overline{\mathrm{S}}}{2 \Delta \bar{\theta}}\right)^{2} \frac{\theta_{1}-\theta_{2}}{\Delta \psi_{0}}
$$


onde $\theta_{1}=\theta\left(\psi_{0,1}\right)$ e $\theta_{2}=\theta\left(\psi_{0,2}\right) ; \Delta \dot{\theta}=\left(\theta_{1}+\theta_{2}\right) / 2-\theta_{n} ; \vec{S}=\left(S_{1}+S_{2}\right) / 2$ e $\Delta \psi_{0}=\psi_{0,1}-\psi_{0,2} .0$ uso da sortividade para o cálculo da condutividade hidráulica também pode ser encontrado em White et al. (1987).

A obtenção de $K$ pelo não leva muito tempo. Os valores de $S$ poderiam ser a limitação do método e serem obtidos pelo método de Warrick (1992) ou através a través da eq. 22 no começo da infiltração. No início da infiltração intervalos de medição de $15 \mathrm{~s}$ foram limitantes na determinação da sortividade no solo estudado por Logsdon \& Jaynes (1993).

\subsubsection{Metodo de Warrick (1992)}

O método tem a vantagem de se poder calcular a sortividade em tempos de infiltração onde o $t_{\text {geom }}$ é pequeno e não é possivel o cálculo de $S_{0}$. Warrick (1992) mostrou que o fluxo de uma fonte circular pode ser aproximado em tempos curtos por:

$$
\frac{\mathrm{Q}(\mathrm{t})}{\pi \mathrm{r}^{2}} \approx 0,5 \mathrm{St}^{-1 / 2}+\frac{0,885 \mathrm{~b}^{-1 / 2} \mathrm{~S}^{2}}{\mathrm{r} \Delta \theta^{2}}
$$

A integração da eq. 30 em relação ao tempo fornece:

$$
\mathrm{I}=\mathrm{St}^{1 / 2}+\frac{0,885 \mathrm{~b}^{-1 / 2} \mathrm{~S}^{2} \mathrm{t}}{\mathrm{r} \Delta \theta^{2}}
$$

a partir da qual S pode ser obtido:

$$
\mathrm{S}=\frac{\mathrm{r} \Delta \theta^{2} \mathrm{t}^{-1 / 2}}{1,31}\left(\left[1+\frac{2,63 \mathrm{I}}{\mathrm{r} \Delta \theta^{2}}\right]^{1 / 2}-1\right)
$$

O método assume que as forças capilares, e portanto $S$, são constantes durante o pequeno tempo no qual a eq. 32 é aplicável. Uma importante contribuição feita por Warrick (1992) foi mostrar que o tempo simulado para atingir fluxo estacionário foi bem maior que os que normalmente são citados na bibliografia. 


\section{MATERIAL E MÉTODOS}

O experimento consistiu na aplicação dos métodos de laboratório: permeâmetro de carga constante (Youngs, 1991), obtenção da condutividade hidráulica a partir da curva de retenção de água no solo (van Genuchten, 1980); e de campo: perfil instantâneo (Hillel et al., 1972), métodos da umidade e do fluxo (Libardi et al., 1980) e infiltrômetro de tensão (Scotter et al., 1982; Ankeny et al., 1991; White et al., 1992; Elrick \& Reynolds, 1992), para a obtenção dos parâmetros requeridos pelos modelos de infiltração. As medições foram realizadas tentando-se diminuir a variabilidade espacial e todos os procedimentos padronizados de tal forma que os resultados possam ser comparáveis.

O experimento de campo e as amostras para determinações de laboratório foram coletadas na Estação Experimental do Instituto Agronômico de Campinas, em Piracicaba, estado São Paulo, Brasil localizada a $22^{\circ} 41^{\prime}$ de latitude sul e $47^{\circ} 39^{\prime}$ de longitude oeste, $554 \mathrm{~m}$ acima do nivel do mar. O clima, segundo a classificação de Köeppen, é do tipo CWa: quente com inverno seco. As médias anuais de temperatura e precipitação são de $21,1^{\circ} \mathrm{C}$ e $1253 \mathrm{~mm}$ respetivamente.

O solo é classificado como Latossolo Vermelho Amarelo de relevo suave ondulado. Os percentuais de argila, silte e areia, a densidade de solo $(\rho)$ e de sólidos $\left(\rho_{s}\right)$ são apresentados na Tabela 1 para as profundidades de interesse. A análise granulométrica foi realizada seguindo a metodologia de rotina do Departamento de Ciência do Solo da ESALQ/USP, densidade de solo e de partículas segundo Blake \& Hartge (1986a e 1986b). 
Tabela 1. Dados de granulometria, densidade do solo ( $\rho)$ e densidade dos sólidos do solo $\left(\rho_{s}\right)$ nas profundidades de interesse.

\begin{tabular}{|c|c|c|c|c|c|}
\hline $\begin{array}{c}\text { Prof. } \\
\text { m }\end{array}$ & $\begin{array}{c}\text { Argila } \\
\mathbf{g ~ k g}^{-1}\end{array}$ & $\begin{array}{l}\text { Silte } \\
\mathbf{g ~ k g}^{-1} \\
\end{array}$ & $\begin{array}{l}\text { Areia } \\
\mathbf{g ~ k g}^{-1} \\
\end{array}$ & 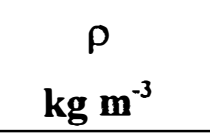 & $\begin{array}{c}\rho_{s} \\
k g \mathbf{m}^{-3}\end{array}$ \\
\hline 0,1 & $399(2,8)$ & $39(50)$ & $561(4)$ & $1568(3,6)$ & $2550(1,8)$ \\
\hline 0,2 & $430(0)$ & $65(17,3)$ & $505(2,2)$ & $1547(3,7)$ & $2640(1,4)$ \\
\hline 0,3 & $490(2,2)$ & $45(24,7)$ & $465(0)$ & $1287(2,6)$ & $2680(2)$ \\
\hline 0,4 & $498(3,8)$ & $45(24,7)$ & $457(2,4)$ & $1297(2,1)$ & $2670(1,8)$ \\
\hline 0,5 & $447(2,4)$ & $43(24,7)$ & $51(2,1)$ & $1287(*)$ & $2590(3,5)$ \\
\hline 0,6 & $479(3,7)$ & $44(25,1)$ & $476(4)$ & $1267(6,3)$ & $2620(1,16)$ \\
\hline 0,7 & $449(4,7)$ & $55(2,4)$ & $496(4,5)$ & $1298(*)$ & $2760(0,5)$ \\
\hline 0,8 & $448(0)$ & $44(24,7)$ & $508(2,1)$ & $1241(0,7)$ & $2610(0,4)$ \\
\hline 0,9 & $454(2,3)$ & $49(21,6)$ & $497(2,1)$ & $1277(3,7)$ & $2650(1,8)$ \\
\hline 1 & $437(4,2)$ & $42(24,7)$ & $521(4)$ & $1254(5,7)$ & $2730(1,8)$ \\
\hline
\end{tabular}

Os valores são médias de três repetições. Valores entre parêntesis são os respetivos coeficientes de variação em porcentagem. (*) não foi possível o cálculo por perda de uma repetição.

\subsection{Determinações de Laboratório.}

\subsubsection{Curvas de retenção da água no solo.}

Foram coletadas 5 amostras indeformadas de 0,072 $\mathrm{m}$ de altura e 0,073 $\mathrm{m}$ de diâmetro numa trincheira nas profundidades de 0,$1 ; 0,2 ; 0,3 ; 0,4 ; 0,5 ; 0,6 ; 0,7 ; 0,8 ; 0,9$; e $1 \mathrm{~m}$ utilizando um dispositivo Uhland conforme Moraes (1991). Cada uma das amostras consistia de três subamostras de $0,024 \mathrm{~m}$ de altura totalizando 15 por camada. Como a curva de retenção foi confeccionada com 11 pontos em cada camada, quatro subamostras ficaram como reserva de segurança.

No ato da coleta, teve-se a precaução de fazer coincidir o ponto médio da altura da amostra com o centro da camada. Após foram acondicionadas em papel alumínio para evitar perdas de umidade e levadas ao laboratório para serem armazenadas a $4^{\circ} \mathrm{C}$ até sua utilização . 
O preparo consistiu em retirar o excesso de terra com uma faca dentada e logo cada anel foi dividido nas três subamostras. Na parte inferior de cada uma foi colocado um pano para evitar perdas de material e contato direto da terra com as placas porosas dos funis de Haines e das câmaras de pressão de Richards. As amostras do centro do anel se utilizaram preferencialmente para pontos de baixas tensões e as dos extremos para altas tensões, levando-se em consideração que na coleta e preparo das amostras os extremos são as partes mas susceptíveis a perturbações na estrutura.

A saturação das amostras foi feita com gotejador de Mariotte (Figura 1) utilizando água destilada e deareada conforme Moraes (1991), com o objetivo de facilitar a dissolução do ar contido dentro da amostra. O gotejamento demorou sempre 24 horas até a água atingir o topo da amostra e permaneciam por mais 24 horas para que as bolhas de ar pudessem sair ou dissolverem-se na água.

Utilizaram-se funis de placa porosa nas tensões 0,$5 ; 1 ; 2 ; 4 ; 6 ; 10$ e $20 \mathrm{kPa}$, e Câmaras de Pressão de Richards nas tensões de 30; 80; 400 e 1500 kPa. A condição de equilíbrio foi atingida entre 2 a 4 dias nos funis de placa porosa; e para as tensões de $80 \mathrm{kPa}, 400 \mathrm{kPa}$ e $1500 \mathrm{kPa}$, em 15, 21 e 48 dias respetivamente. Cada ponto da curva de retenção foi feito com amostras diferentes da mesma camada para agilizar as determinações. Depois de atingido o equilíbrio, o conteúdo hídrico foi obtido gravimétricamente (Gardner, 1986).

Os dados obtidos foram ajustados á eq. 9 (van Genuchten, 1980) utilizando o programa computacional SWRC (Dourado Neto et al., 1990). O parâmetro de ajuste $\theta_{s}$ foi considerado igual ao conteúdo hidrico de imbebição a $0,5 \mathrm{kPa}$ de tensão, e $\theta_{\mathrm{r}}$ interpolado pelo programa. As curvas foram ajustadas levando em conta a restrição $m=1-1 / n$ (Mualem, 1976) para cálculo da condutividade hidráulica relativa, $K_{r}$, a partir da eq. 10 proposta por van Genuchten (1980).

\subsubsection{Condutividade hidráulica saturada e densidade do solo.}

Com o mesmo procedimento descrito em 3.1.1, na mesma trincheira e profundidades foram coletadas 3 amostras de $0,072 \mathrm{~m}$ de altura e $0,073 \mathrm{~m}$ de diâmetro 
por camada. As amostras foram utilizadas para determinação da condutividade hidráulica saturada pelo método do permeâmetro de carga constante (Youngs, 1991), e densidade do solo (Blake \& Hartge, 1986a), (Figura 1). O procedimento de preparo das amostras e saturação foi similar ao utilizado na confecção das curvas de retenção.

Após a saturação, as amostras eram levadas ao dispositivo mostrado na Figura 1. Em cada amostra era mantida uma carga constante de aproximadamente $3,5 \mathrm{~cm}$ de coluna de água através da utilização de frascos de Mariotte. $O$ volume de água coletada era medido com proveta em intervalos de tempo determinados e quando de 3 a 5 medições consecutivas de vazão davam resultados semelhantes, se considerou que o fluxo era estacionário.

Uma vez atingido o equilíbrio, foi calculado o fluxo como:

$$
q=\frac{Q}{A t}
$$

onde $q$ representa o fluxo $\left[\mathrm{MT}^{-1}\right] ; Q$, vazão $\left[\mathrm{M}^{3} \mathrm{~T}^{-1}\right] ; t$, tempo $\left[\mathrm{T}^{-1}\right]$ e $A$ área da seção reta da amostra. Foi utilizada a equação de Darcy-Buckingham para o cálculo da condutividade hidráulica:

$$
\mathrm{K}_{\mathrm{sat}}=\frac{\mathrm{q}}{\frac{\mathrm{d} \psi_{\mathrm{t}}}{\mathrm{dz}}}
$$

sendo $\mathrm{d} \psi_{\curlywedge} / \mathrm{d} z \circ \mathrm{o}$ gradiente de potencial hidráulico. 

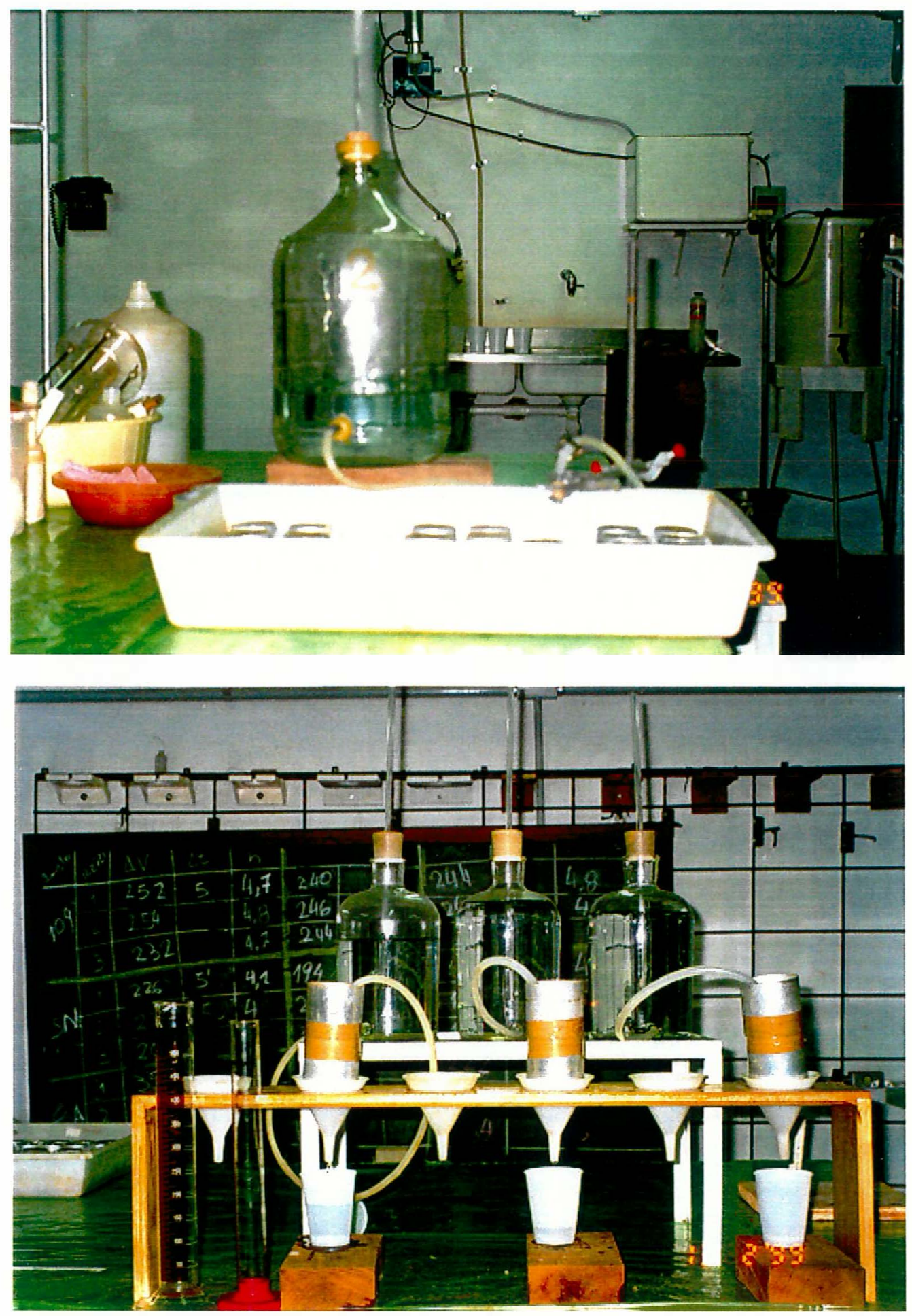

Figura 1. Saturação de amostras indeformadas utilizando sistema de gotejamento e determinação de condutividade hidráulica pelo método do permeâmetro de carga constante. 


\subsection{Determinações de campo}

\subsubsection{Método da drenagem interna}

O solo foi submetido a um estudo de drenagem profunda para obter os parâmetros $K_{O}, \gamma$, e $\theta_{O}$, da equação $K(\theta)=K_{O} \exp \gamma\left(\theta-\theta_{0}\right)$ utilizando os métodos do perfil instantâneo (Hillel et al., 1972); da umidade e do fluxo (Libardi et al., 1980). Os três métodos exigem que sejam satisfeitas as seguintes condiçōes de contorno durante 0 processo de redistribuição:

$$
\left\{\begin{array}{lll}
\theta=\theta(z), & t=0, & z=0 \\
\theta=\theta_{n}, & t>0, & z=\infty \\
q=0, & t>0, & z=0
\end{array}\right.
$$

Para tal finalidade foi demarcada uma área circular de $5 \mathrm{~m}$ de diâmetro confinada por uma chapa galvanizada de $0,5 \mathrm{~m}$ de altura inserida no chão até cerca de $0,1 \mathrm{~m}$. No centro da área foram instaladas duas baterias de tensiômetros (denominadas bateria de tensiometros da esquerda e da direita de acordo com a posição dos manômetros) nas profundidades de 0,$1 ; 0,2 ; 0,3 ; 0,4 ; 0,5 ; 0,6 ; 0,7 ; 0,8$ e 1 $\mathrm{m}$ (Figura 2). A disposição foi feita de tal forma que os mais profundos ficassem no centro da área e os mais rasos na lateral. Dois manômetros de mercúrio foram instalados dentro do círculo, e nivelados de tal forma que as cubas de mercúrio ficassem na mesma altura; também se levou em consideração a posição dos manômetros em relação ao sol para que no horário de leitura se evitasse 0 aquecimento dos mesmos.

Para favorecer o processo de saturação por ocasião do início do ensaio de condutividade hidráulica foi feito um pre-molhamento com $3 \mathrm{~m}^{3}$ de água, tentando-se melhorar a redistribuição da água e conseqüêntemente a saturação dos poros pequenos. Decorridos sete dias foram adicionados mais $9,8 \mathrm{~m}^{3}$ de água, quantidade estimada para saturar até um metro de profundidade (Figura 3). 


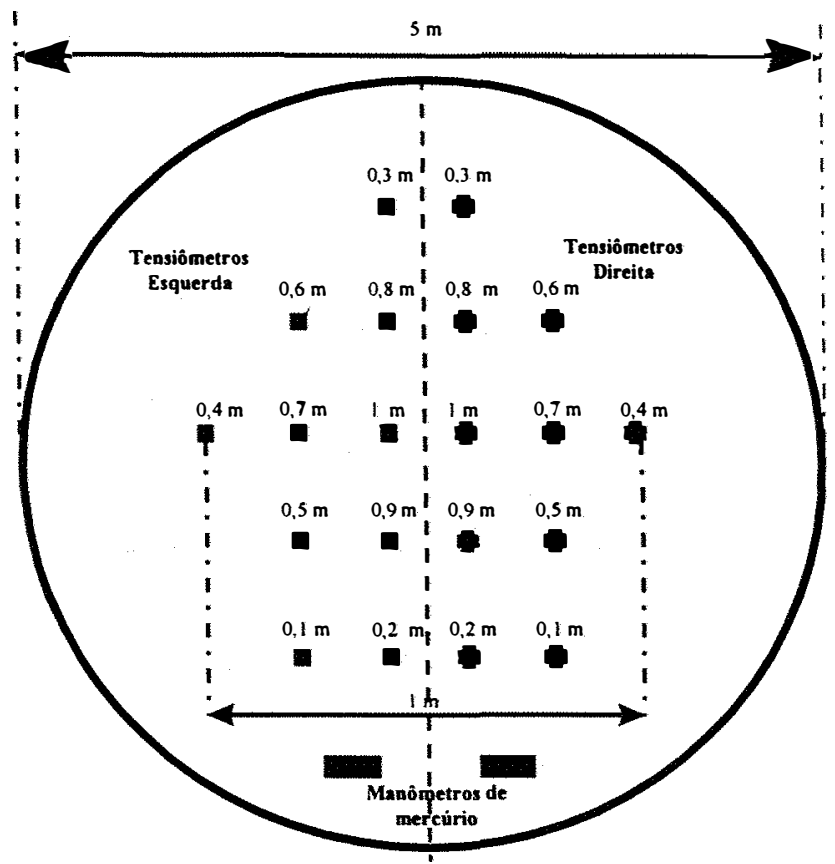

Figura 2. Disposição dos tensiômetros e manômetros de mercúrio na área confinada. ( $O$ desenho não se encontra em escala).

Terminada a infiltração, cobriu-se a área com dois plásticos de polietileno, um colocado acima do outro, sendo o inferior de $6 \times 6 \mathrm{~m}^{2}$ e o superior de $8 \times 8 \mathrm{~m}^{2}$. O procedimento foi feito para satisfazer a condição de ausência de evaporação na superficie e evitar a entrada de água proveniente de chuvas ou escoamento superficial na zona confinada (Figura 3).

O plástico foi furado para dar passagem aos tensiômetros e manômetros e em seguida procedeu-se a sua amarração com arame em torno dos equipamentos. Em volta dos manômetros e parte superior dos tensiômetros foi colocada fita adesiva para evitar a entrada e saída de água. O perimetro do plástico foi coberto com terra o que evitou também entradas de água. Finalmente, as lonas plásticas foram cobertas com palha de cana para minimizar o aquecimento e conseqüêntemente a possivel, a formação de bolhas de ar nos tubos de PVC dos tensiômetros e o efeito da temperatura no fluxo de água. 

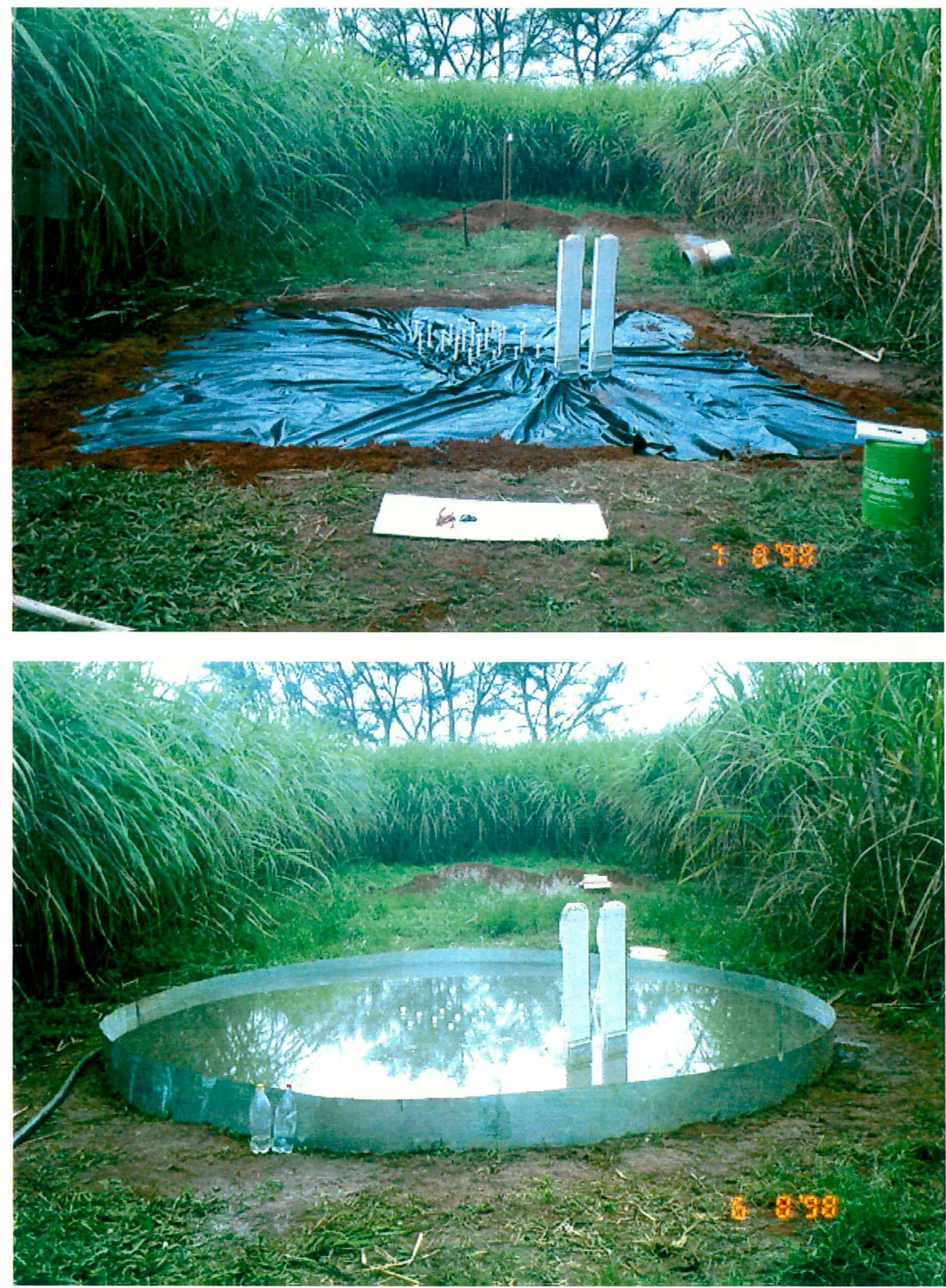

Figura 3. Área coberta após a inundação com o objetivo de saturar o perfil de solo até um metro de profundidade e logo protegida com plástico de polietileno preto para evitar evaporação e entradas de água. 
A drenagem interna foi observada por meio das leituras dos tensiômetros com manômetros de mercúrio. Os valores das leituras em altura das colunas de mercúrio $\left(m_{\mathrm{Hg}}\right)$ foram transformados em potencial matricial segundo:

$$
\psi_{m}=-12,6 \mathrm{H}+\mathrm{h}_{\mathrm{c}}+\mathrm{z}
$$

sendo $\mathrm{H} \circ$ valor da leitura, $h_{c}$ altura da cuba de mercúrio e $z$ a profundidade de instalação do tensiômetro. Ao serem instalados os manômetros na mesma altura, como mencionado anteriormente, iguais valores de $h_{c}$ nas baterias de tensiômetros facilitaram os cálculos. A Figura 4 apresenta a disposição de coleta de amostras, e dos locais de instalação dos tensiômetros no campo.

O tempo inicial $(t=0)$ foi considerado aquele no qual as leituras dos manômetros apresentaram-se correspondentes ao potencial zero ou negativo. A partir desse momento foram realizadas leituras espaçadas por intervalos de uma hora no início e logo diárias quando as variações das medições eram pequenas (a cada 2 a 3 dias). O experimento se estendeu por 40 dias, quando suspendeu-se devido a variações extremamente reduzidas nas leituras. Estas foram realizadas entre as 7:30 e 8:30 h da amanha, horários posteriores de leitura resultaram em absurdos possivelmente devido ao aquecimento de manômetros, tensiômetros, ar e água dentro dos espaguetis etc.

Os respetivos valores de umidade volumétrica do solo nos diversos tempos de drenagem foram inferidos a partir das curvas de retenção construídas em laboratório conforme apresentado no item 3.1.1. Com os dados de evolução da umidade com o tempo em cada camada foram feitos os cálculos correspondentes. Libardi (1995), apresenta um roteiro para a aplicação dos métodos do perfil instantâneo, da umidade e do fluxo. 


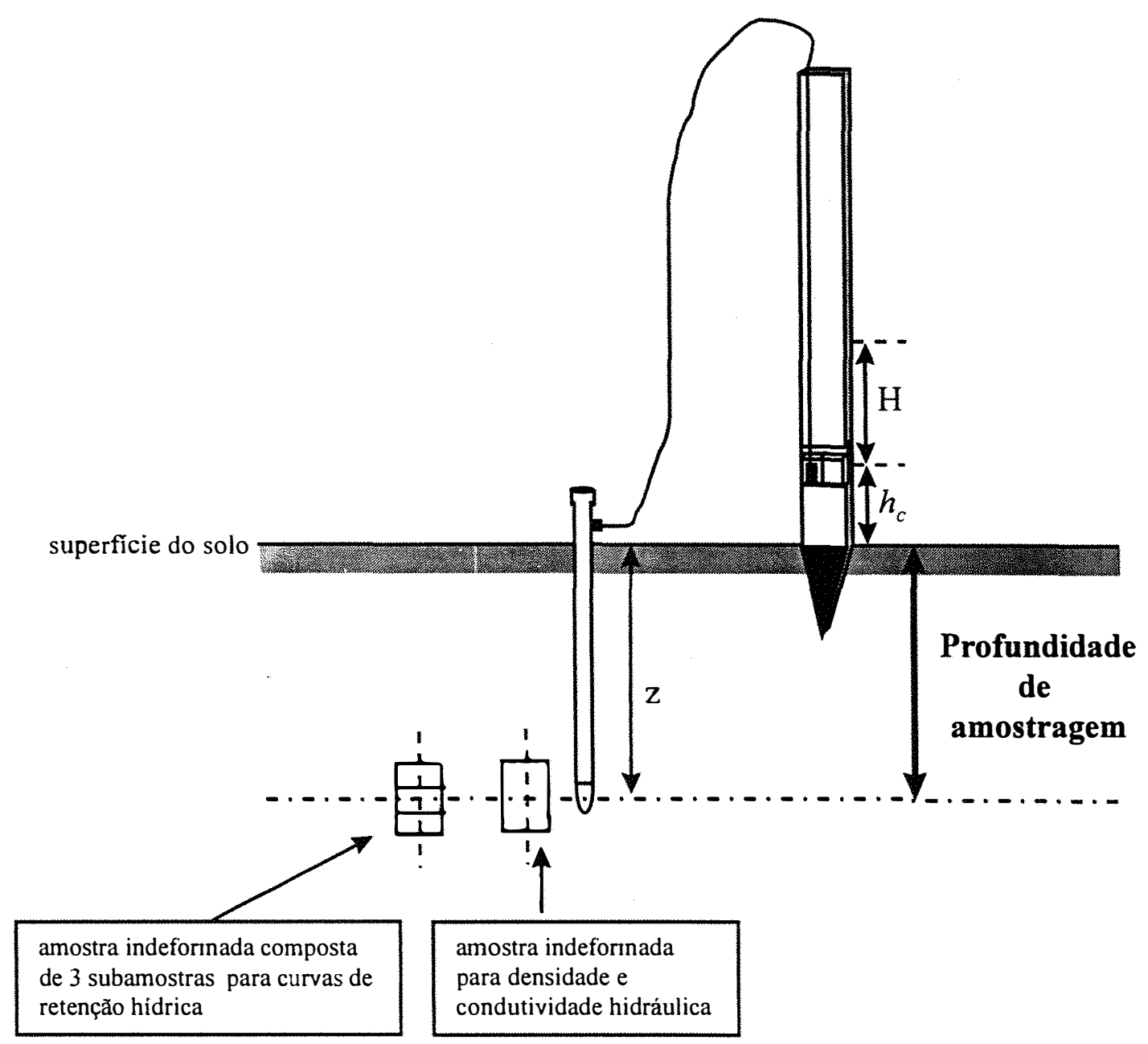

Figura 4. Representação das posições de coleta de amostra e dos locais de instalação dos tensiômetros no campo.

\subsubsection{Método utilizando o infiltrômetro de tensão}

Utilizou-se um infiltrômetro similar ao apresentado por Perroux \& White (1988), Figura 5. O infiltrômetro consta basicamente de dois reservatórios, um que contem um volume de água necessária à infiltração e outro de despressurização (tipo frasco de Mariotte). O reservatório de despressurização possui dois tubos internos, um móvel que permite fluxo de ar do exterior do aparelho quando em funcionamento e 0 outro conectado ao reservatório de água. O reservatório de água se encontra conectado à base circular e tem uma régua com a qual se fazem as medições de vazão. O contato com o solo é feito por meio de um tecido de náilon ("silk-screen": 200 
fios por $\mathrm{cm}^{2}$ ) preso ao infiltrômetro por uma borracha. Uma tela metálica entre o náilon e o disco, assegura que a superfície de contato entre o aparelho e o solo seja plana.

A tensão $(\tau)$ na base do infiltrômetro é controlada variando-se a distância $h_{1}$, entre o tubo móvel e o nível de água. No momento da infiltração o reservatório encontra-se fechado no topo e o tubo móvel de ajuste de tensão aberto. Quando um volume de água é absorvido pelo solo, o reservatório fica com uma diferença de pressão que tem que ser compensada pela entrada de uma bolha de ar pelo tubo móvel. A vazão é medida com a régua colada no reservatório principal.

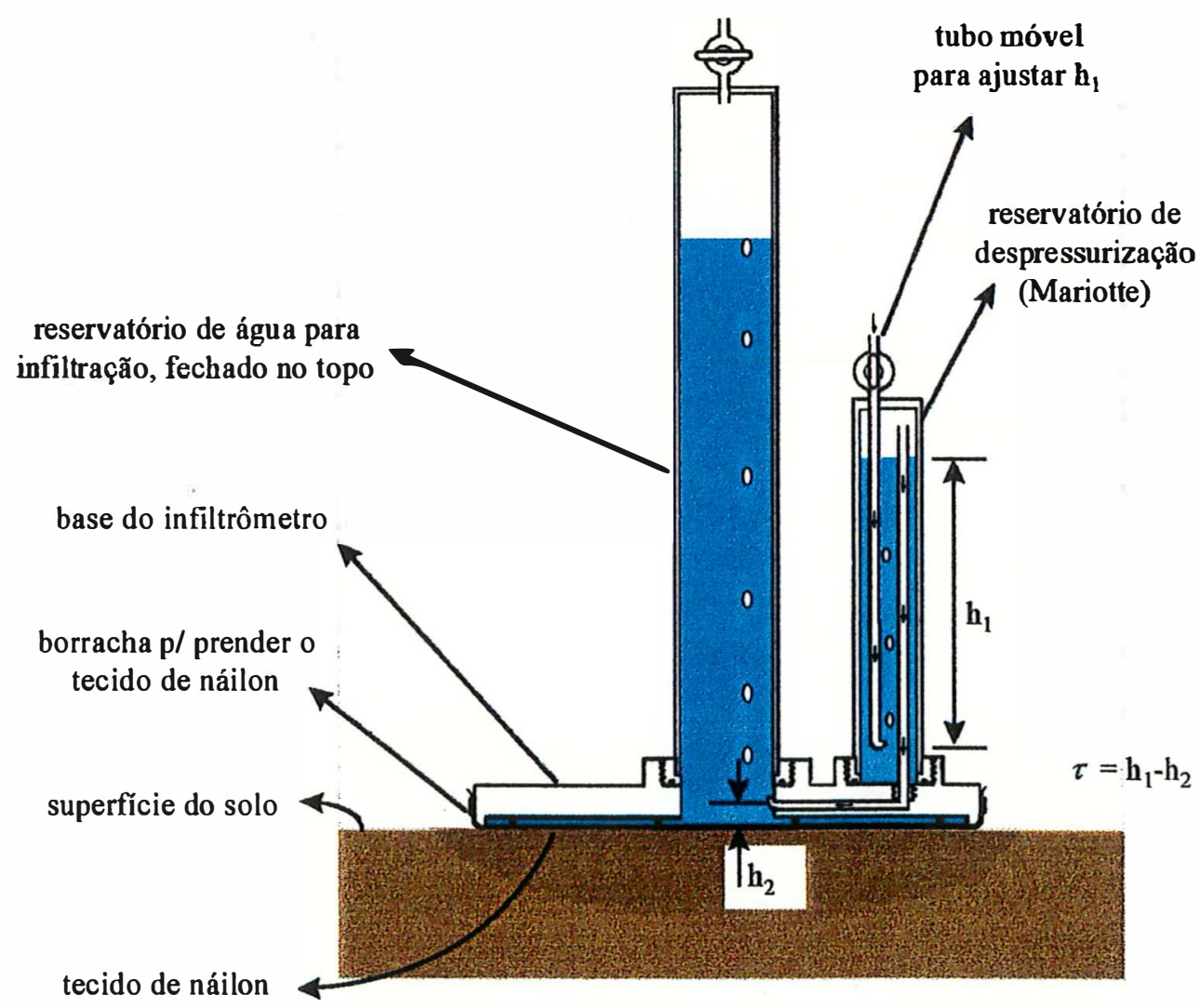

Figura 5. Infiltrômetro de tensão (Perroux \& White, 1988) em funcionamento. Observa-se que o tubo móvel se encontra aberto e o reservatório principal fechado à atmosfera. As flechas dentro do tubo de despressurização indicam o sentido do fluxo de ar.

No ato de medição, primeiro ajusta-se a tensão com o tubo móvel que ajusta $h_{1}$, levando em conta que $\tau=h_{1}$ - $h_{2}$ (Figura 5). Em seguida procede-se ao enchimento 
do reservatório de água, devendo-se para tanto fechar o tubo móvel e abrir o tubo do reservatório principal. $O$ infiltrômetro foi introduzido numa bacia de água e esta foi succionada até encher 0 aparelho, acabado o processo, foi fechado o tubo do reservatório principal rapidamente.

A superficie de medição foi aplainada e posteriormente adicionada uma camada uniforme de areia $(<0,01 \mathrm{~m})$ para favorecer o bom contato do aparelho com 0 solo (Figura 6). Os pedriscos e raizes foram eliminados cuidadosamente para evitar rupturas na tela de náilon do infiltrômetro. Em seguida, se abriu o tubo móvel que ajusta $h_{1}$, o infiltrômetro foi tomado da base, colocado na superficie preparada e levemente pressionado para assegurar o contato com o solo. Depois de 15 a 30 segundos, quando a areia ficou umedecida, iniciaram-se as leituras.

Se deve ter extremo cuidado para que no momento em que se fazem as medições não entre ar no aparelho, exceto pelo tubo móvel que ajusta $h_{I}$. A entrada de ar pelas uniões das partes do aparelho podem ser confirmadas pela presença de bolhas de ar e, como medida de prevenção, em todas as uniões e conexões do infiltrômetro foi colocada uma camada de vaselina em pasta.

Foram realizadas quatro repetições na camada de 0-0,1 m, nas tensões 0,1 ; 0,05; 0,025 e $0 \mathrm{kPa}$ nessa ordem e no mesmo local utilizando-se dois infiltrômetros de raios $r_{1}=11,3 \mathrm{~cm}$ e $r_{2}=3,8 \mathrm{~cm}$. Cada amostragem foi realizada o mais próximo uma de outra tentando-se diminuir a variabilidade espacial (Figura 6).

No começo da infiltração a freqüência de leitura foi de 15 a $30 \mathrm{~s}$ dependendo dos casos e do raio do infiltrômetro, com o decorrer do tempo os intervalos foram aumentando. O tempo para atingir fluxo estacionário foi aproximadamente $1 \mathrm{~h}$ em tensões altas diminuindo, em tensões baixas. Foi considerado que o equilibrio era atingido quando pelo menos cinco leituras consecutivas apresentavam resultados similares.

As leituras foram muitas vezes dificeis e as prováveis causas foram interferência das bolhas de ar formadas cada vez que um volume de água sai do aparelho, tamanho da escala de medida, freqüência de leitura, etc. As vezes foi difícil conseguir que toda a 

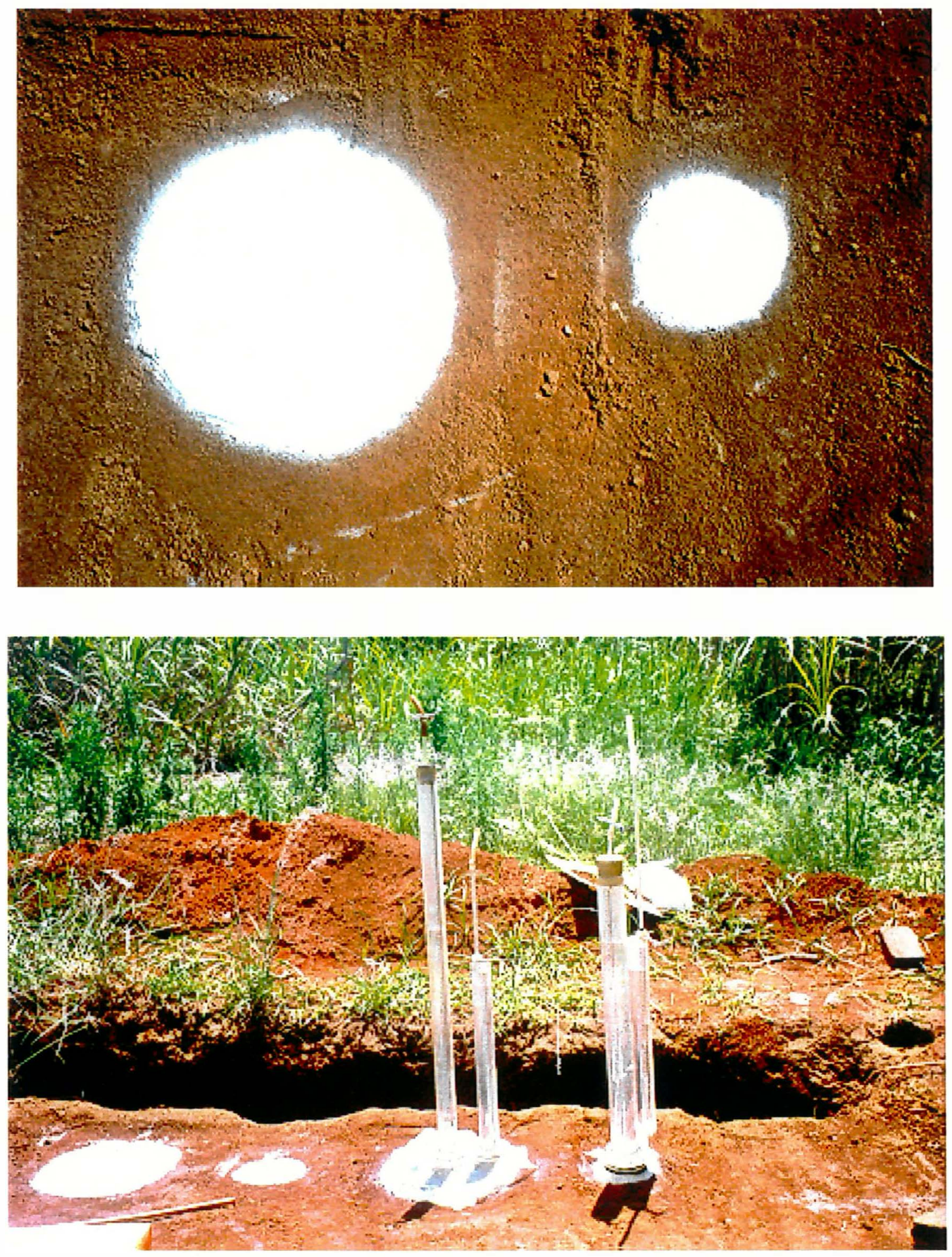

Figura 6. Área preparada para um ensaio e o infiltrômetros em funcionamento no processo de medição. 
base ficasse em contato com o solo, especialmente quando se utilizou o infiltrômetro de base maior. Se isto não acontece, as estimativas de fluxo são errôneas.

Antes de cada medição foi tomada a umidade inicial $\left(\theta_{n}\right)$ do solo pelo método gravimétrico (Gardner, 1986) perto do local de medida. Como as medições das quatro tensões $(1 ; 0,5 ; 0,25$ e $0 \mathrm{kPa})$ que constituíram cada repetição foram feitas no mesmo local não foi possível estimar a umidade final $\left(\theta_{0}\right)$ correspondente a cada tensão pelo método gravimétrico. Por tal motivo a umidade ao final do ensaio de infiltração foi estimada interpolando-a da curva de retenção hidrica na profundidade de $0,1 \mathrm{~m}$, similar ao apresentado por Smetten \& Clothier (1989).

A partir dos valores de fluxo estacionário da infiltração tridimensional, $q_{\infty}[M T \cdot$ '] obtidas para as quatro tensōes fizeram-se os cálculos utilizando a metodologia de Ankeny et al. (1991) e Scotter et al. (1982) apresentadas em detalhe no Anexo 1.

$\mathrm{Na}$ determinação da condutividade hidráulica utilizando-se um infiltrômetro de disco de raio $\mathrm{r}$ em duas tensões $\left(\tau_{1}\right.$ e $\tau_{2}$ ) segundo Ankeny et al. (1991) foi calculado $\alpha$ partir da eq. A15, pág.65. A seguir, substituindo o valor de $\alpha$ nas eq. A12 e A13, pág. 65 , foi obtida a condutividade hidráulica para as tensões correspondentes. Foram escolhidos pares consecutivos de tensōes $\left(\tau_{1}\right.$ e $\tau_{2}$ ) e como no experimento utilizaramse quatro $(1 ; 0,5 ; 0.25: 0 \mathrm{kPa})$, para cada uma das tensões intermediárias podem-se obter dois valores de condutividade hidráulica. Nestes casos, conforme sugere Ankeny et al. (1991), a condutividade hidráulica correspondente a uma tensão intermediária pode ser estimada calculando a média dos dois valores de $K$ obtidos.

Na determinação da condutividade hidráulica utilizando dois infiltrômetros de disco de raios diferentes, $r_{1}$ e $r_{2}$, numa tensão $\tau$ ( Scotter et al., 1982) foi utilizada a eq. A19, pág. 66. A sortividade foi calculada a partir da eq. A21, pág. 67 (White \& Sully, 1987) utilizando as umidades inicial e final medidas experimentalmente, e o potencial de fluxo mátrico estimado a partir da eq. A20, pág. 67. 


\section{RESULTADOS E DISCUSSÃO}

\subsection{Metodologia de laboratório}

Os dados de conteúdo hidrico em função do potencial matricial foram bem ajustados pela equação de van Genuchten (1980) na faixa de 0,5 kPa a $1500 \mathrm{kPa}$ (Figura 7). Nenhum dos onze pontos de cada curva precisou ser refeito ou eliminado, sendo o fato um bom indicador de que a curva de retenção pode ser confeccionada com diferentes subamostras para cada tensão.

Ao se utilizar uma amostra por ponto, otimizou-se o tempo operativo no laboratório e não submetendo as amostras à operações repetidas de resaturação e novas tensões houve uma minimização das alterações sobre as mesmas, ainda assim foi observada uma certa dispersão dos pontos experimentais em relação à linha de ajuste. Na Tabela 2 são apresentados os parâmetros de ajuste da equação de van Genuchten (1980).

Tabela 2. Parâmetros de ajuste da equação de van Genuchten (1980) correspondentes as diferentes camadas do perfil em estudo.

\begin{tabular}{ccccccccccc} 
& \multicolumn{10}{c}{$\mathbf{z}(\mathbf{m})$} \\
\hline Parâmetro & $\mathbf{0 , 1}$ & $\mathbf{0 , 2}$ & $\mathbf{0 , 3}$ & $\mathbf{0 , 4}$ & $\mathbf{0 , 5}$ & $\mathbf{0 , 6}$ & $\mathbf{0 , 7}$ & $\mathbf{0 , 8}$ & $\mathbf{0 , 9}$ & $\mathbf{1 , 0}$ \\
\hline$\alpha$ & 1,812 & 0.953 & 0.885 & 1.434 & 0,739 & 0,667 & 0,621 & 0,332 & 0,407 & 0,430 \\
$\mathbf{n}$ & 1.298 & 1.375 & 1.585 & 1.511 & 1,429 & 1,587 & 1,618 & 1,84 & 1,959 & 1,745 \\
$\theta_{\mathbf{r}}$ & 0,152 & 0.201 & 0.232 & 0.240 & 0,183 & 0,215 & 0,192 & 0,182 & 0,180 & 0,174 \\
$\theta_{\mathbf{s}}$ & 0.475 & 0.418 & 0.493 & 0.481 & 0.460 & 0,474 & 0,491 & 0,483 & 0,489 & 0,495 \\
\hline
\end{tabular}



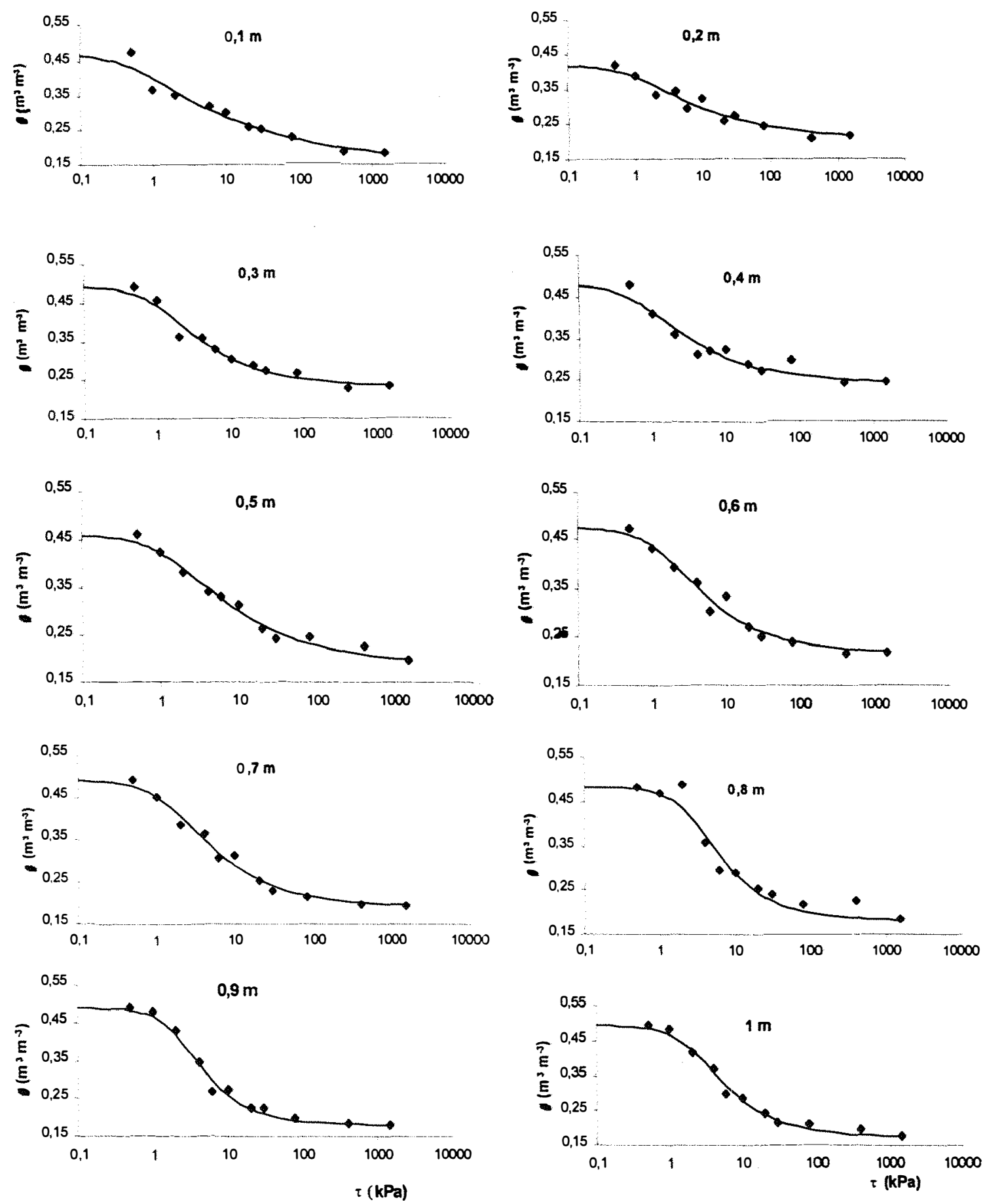

Figura 7: Curvas de retenção hidrica do perfil do solo em estudo.

A altura da amostra é outro fator a ser considerado na confecção das curvas de retenção podendo ser feitas duas observações importantes. Primeiro, a 
determinação do conteúdo hidrico a baixas tensões é dificil pela grande influência do gradiente gravitacional ao longo da amostra (Bouma, 1991). Segundo, o tempo para atingir ao equilibrio cresce em forma quadrática com o acréscimo da altura da amostra (Klute, 1986). Como foram utilizadas subamostras de $0,024 \mathrm{~m}$ de comprimento, foi minimizado o erro na determinação do conteúdo hídrico a baixas tensões e o tempo para atingir o equilibrio foi comparativamente menor do que se tivessem sido utilizados amostras de maior altura. O último aspecto teve maior relevância quando foram feitas as determinações em tensões altas porque o tempo para atingir o equilibrio foi maior que em tensões baixas (Exemplo: 48 dias a $1500 \mathrm{kPa}$ versus 2 dias a 0,5 kPa).

A eleição do conteúdo hídrico a $0,5 \mathrm{kPa} \operatorname{como} \theta_{\mathrm{s}}$ para fazer o ajuste das curvas mostrou-se satisfatória. O valor $\theta_{s}$ (Tabela 2) é um parâmetro de ajuste que tem a interpretação física de conteúdo hidrico de imbebição mas não representa conteúdo hidrico de saturação. Quando comparado com os valores de porosidade total calculada a partir da densidade do solo e dos sólidos ( $P T=1-\rho / \rho_{s}$, Tabela 1$)$, observa-se que são menores salvo nas camadas de 0,1 e 0,2 m (Tabela 3). A porosidade total calculada poderia ser uma boa estimativa do conteúdo hídrico de saturação levando em consideração que os coeficientes de variação foram menores que $10 \%$, valor citado por Kutilek \& Nielsen (1994) como carateristico para esta propriedade, e foram maiores que o conteúdo hídrico de imbebição salvo nas camadas mencionadas.

Coincidentemente, os menores valores de porosidade total apresentaram-se nas camadas de 0,1 e 0,2 m onde se observaram as maiores densidades do solo. É de se esperar portanto que nessa camada o comportamento hidráulico seja diferente das demais camadas. As curvas de retenção mostradas na Figura 7 apresentam um rápido declinio da umidade quando aplicadas tensões relativamente baixas, variando muito pouco em tensões acima de $10 \mathrm{kPa}$, salvo nas camadas de 0,1 e 0,2 m que apresentaram maior densidade que as restantes (Tabela 1). 
Tabela 3. Porosidade total do solo nas diferentes profundidades do perfil em estudo.

\begin{tabular}{ccc}
\hline $\begin{array}{c}\text { Profundidade } \\
(\mathbf{m})\end{array}$ & $\begin{array}{c}\text { Porosidade total } \\
\left(\mathbf{m}^{\mathbf{3}} \mathbf{m}^{-3}\right)\end{array}$ & $\begin{array}{c}\mathbf{C . V} . \\
\mathbf{( \% )}\end{array}$ \\
\hline 0.1 & 0,385 & 8,7 \\
0.2 & 0,414 & 7,2 \\
0.3 & 0,520 & 4,2 \\
0.4 & 0,515 & 3,7 \\
0.5 & 0,504 & $\left(^{*}\right)$ \\
0.6 & 0,516 & 7,1 \\
0.7 & 0,529 & $(*)$ \\
0.8 & 0,525 & 1,0 \\
0.9 & 0,519 & 5,1 \\
1 & 0,541 & 6,4 \\
\hline
\end{tabular}

Os valores são médias de três repetições. $(*)$ não foi possível o cálculo por ter-se perdido uma repetição.

A partir da curva de retenção hidrica foi determinada a distribuição do tamanho dos poros no solo. Para facilitar a interpretação foi derivada ${ }^{1}$ a eq. (9) (pág. 10) e confeccionada a Figura 8. Como a diferencial da curva de retenção de água no solo representa a variação de conteúdo hidráulico em função da variação da tensão, o ponto de máximo corresponde ao tamanho de poros que ocorrem com maior freqüência. Considerando um intervalo constante de tensão $(\Delta \tau)$ de 0,5 kPa pode-se observar que o pico da curva esteve à esquerda da tensão de $1 \mathrm{kPa}$ nas profundidades de 0.1 a $0.5 \mathrm{~m}$ e a partir dos $0,6 \mathrm{~m}$ à direita. Os dados de granulometria, densidade do solo (Tabela 1), a distribuição dos diâmetros dos poros do perfil derivadas da curva de retenção hídrica (Figura 8) e a porosidade total calculada (Tabela 3) sustentam a observação de que o solo não é homogêneo e portanto podese esperar que as características hidráulicas sejam diferentes nas distintas camadas do solo.

$\frac{d \theta}{d \psi_{m}}=\left(\theta_{r}-\theta_{s}\right)\left[1+\left(\psi_{m} \alpha\right)^{n}\right]^{(-m-1)} m n \alpha^{n}\left(\psi_{m}\right)^{n-1}$ 
$0.1 \mathrm{~m}$

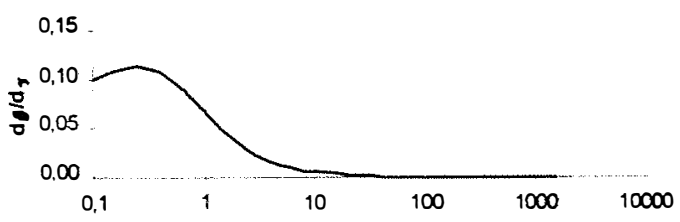

$0,3 m$

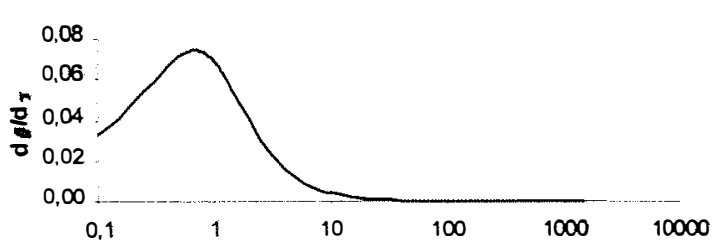

$0,5 \mathrm{~m}$

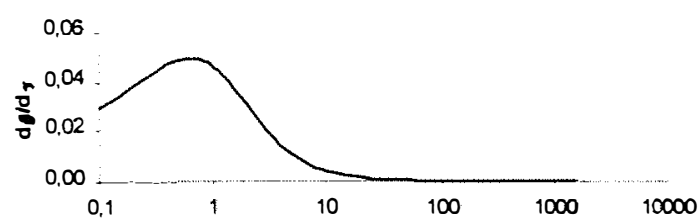

$0,7 \mathrm{~m}$

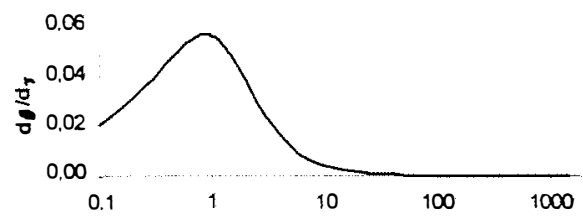

Q99

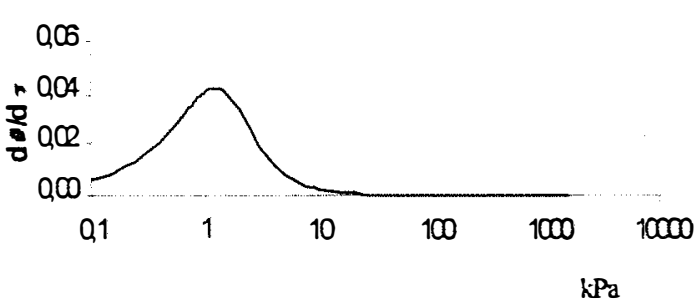

$0,2 m$

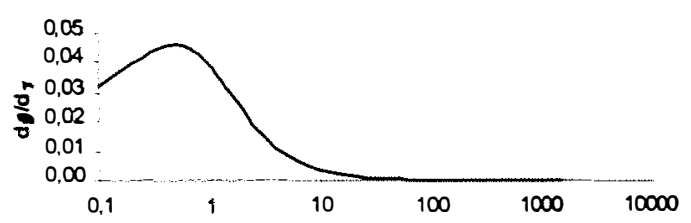

$0,4 \mathrm{~m}$

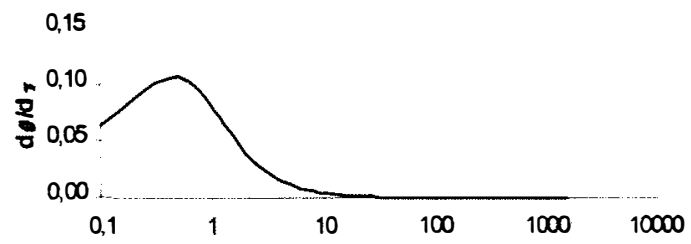

$0,6 \mathrm{~m}$

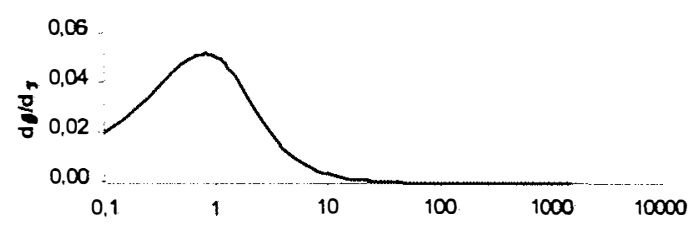

$0,8 \mathrm{~m}$

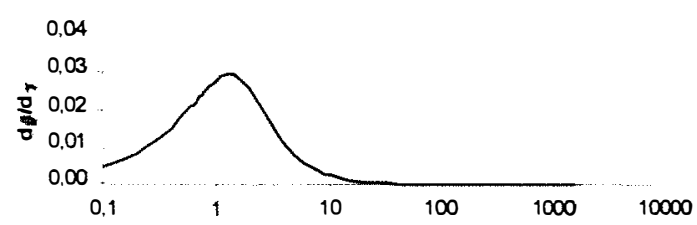

1

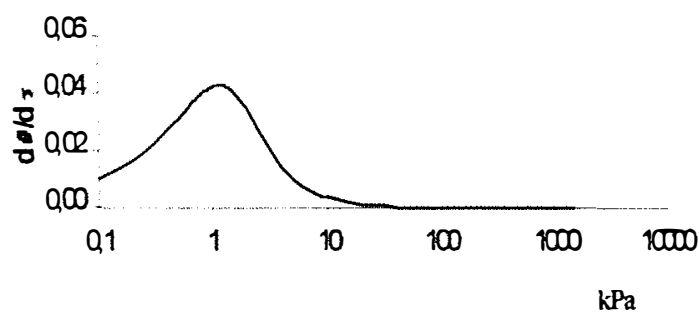

Figura 8. Distribuição de poros obtida a partir das curvas de retenção de água no solo. 
A Tabela 4 mostra as condutividade hidráulicas obtidas com o permeâmetro de carga constante no laboratório. Klute \& Dirksen (1986) apresentam que a metodologia do permeâmetro de carga constante é apropriada para solos de textura argilo arenosa e condutividade hidráulica da ordem de grandeza $10^{-2}$ a $10^{-7} \mathrm{~m} \mathrm{~s}^{-1}$, características coincidentes com as utilizadas no estudo.

O alto coeficiente de variação da propriedade é um dos principais inconvenientes na sua determinação e posterior utilização. As condutividade hidráulicas saturada e não saturada na maioria das vezes têm coeficientes de variação maiores que $100 \%$ (Kutilek \& Nielsen, 1994). A Tabela 4 mostra valores menores talvez por terem sido tomadas amostras próximas, o que tornou questionável a independência espacial das amostras pertencentes a uma mesma camada, é de se supor portanto que sejam semelhantes.

Tabela 4. Condutividade hidráulica saturada obtida em laboratório pelo método do permeâmetro de carga constante utilizando amostras indeformadas.

\begin{tabular}{ccc}
\hline $\begin{array}{c}\text { Prof. } \\
\mathrm{m}\end{array}$ & $\begin{array}{c}\boldsymbol{K}_{\text {sat }} \\
\mathrm{m} \mathrm{s}^{-1}\end{array}$ & $\begin{array}{c}\text { C.V } \\
\%\end{array}$ \\
\hline 0.1 & $5,5 \cdot 10^{-5}$ & 26,5 \\
0.2 & $1,83.10^{-4}$ & 21,5 \\
0.3 & $1.37 .10^{-4}$ & 30,8 \\
0.4 & $9.42 \cdot 10^{-5}$ & 83,6 \\
0.5 & $1,23.10^{-4}$ & $*$ \\
0.6 & $7,75 \cdot 10^{-5}$ & 52,2 \\
0.7 & $3,94.10^{-5}$ & $*$ \\
0.8 & $9.25 \cdot 10^{-5}$ & 60,7 \\
0.9 & $9.14 .10^{-5}$ & 67,2 \\
1 & $5,86.10^{-5}$ & 60,6 \\
\hline
\end{tabular}

Mohanty et al. (1998) atribuiu uma maior variabilidade do método do laboratório ao pequeno volume da amostra, à quantidade de macroporos presentes e à compactação durante a extração quando comparado com métodos "in situ" como o permeâmetro de Guelph ou infiltrômetros de tensão. A extração e preparo da amostra 
também pode resultar em alterações na medição causadas por perturbações e selamento dos macroporos (Jarvis \& Meesing, 1995).

Outro aspecto de importância na determinação da propriedade é o volume da amostra, tendo que ser adaptado ao sistema poroso a ser medido, e conter um número representativo de cada classe de poros (Lauren et al., 1988). Paige \& Hillel (1993) discutem que diferentes escalas de medida podem alterar o efeito que a estrutura do solo e os macroporos têm na condutividade hidráulica. Além, ao isolar a amostra de uma camada, a interpretação dos resultados pode ser difícil por não ser considerada a continuidade vertical dos macroporos (Bouma et al., 1977; Timlin et al., 1994) e as medições num horizonte particular serem isoladas dos outros horizontes do perfil do solo (Bouma, 1982).

Combinando os valores de $K_{\text {Sat }}$ da Tabela 4 e a eq. 10 (pág. 11) podem ser obtidos os valores da condutividade hidráulica em função do conteúdo hídrico, mas a eleição da condutividade hidráulica saturada não é conveniente por ter a medida um alto desvio padrão (Dirksen, 1991). Embora o autor não explicite a ordem de grandeza do desvio, Warrick \& Nielsen (1980) citam que o coeficiente de variação para a condutividade hidráulica saturada pode ser superior a $100 \%$ e classificam o parâmetro como de alta variação. Torna-se difícil então, a obtenção da condutividade hidráulica saturada que permita o cálculo de $K(\theta)$ utilizando a eq. 10 (pág. 11) (van Genuchten, 1980).

Muitos autores resaltam a importância do fluxo preferencial pelos macroporos (Bouma, 1991; Miyazaki, 1993; McCoy et al., 1994). Na tentativa de conseguir melhoras na quantificação da condutividade hidráulica foram propostas soluções considerando-a como o somatório do fluxo pelos macroporos e pela matriz do solo (Chen et al., 1993). Othmer et al. (1991) a partir de um solo com distribuição de poros bimodal estimou a condutividade hidráulica considerando os sistemas porosos inter e intragregados separadamente utilizando o procedimento de van Genuchten (1980). Considerando que a distribuição de poros é unimodal (Figura 8) não se justificaria a aplicação deste tipo de modelos. Embora a colocação deva ser feita, 0 assunto requer mais estudos que vão além dos objetivos do presente trabalho. 


\subsection{Métodos de campo}

\subsubsection{Método da drenagem interna}

A Figura 9 apresenta a evolução do conteúdo hidrico no perfil de solo para os diferentes tempos de redistribuição. Pode ser observado que a faixa de umidade na qual são feitas as medições é menor que a representada pelos parâmetros $\theta_{\mathrm{s}}$ e $\theta_{\mathrm{r}}$ obtidos no ajuste da curva de retenção ao modelo de van Genuchten (1980) (Tabela 2).

Em muitos casos, é possivel que o solo não fique saturado devido ao ar aprisionado (Skaggs \& Khaleel, 1982) e portanto a taxa de infiltração não pode ser aproximada a $K_{\text {sat }}$. $O$ apresentado na Figura 9 pode ser reforçado observando-se que a umidade inicial (Tabela 5) esteve entre 70 e $90 \%$ da porosidade total (Tabela 3), coincidindo com Chong et al. (1981); Dirksen, (1991); Arya et al., (1998) que apresentaram valores não superiores a $90 \%$.

Além do ar que pode ficar aprisionado no solo, outra razão pela qual é dificil atingir o conteúdo hídrico inicial igual ao de saturação é que o tempo inicial é um valor experimental dificil de medir (Reichardt et al., 1998). Um dos problemas detectados foi que no inicio da infiltração a resposta dos tensiômetros é diferente e portanto dificil determinar o tempo no qual considerar o inicio das determinações. Tentou-se escolher como tempo inicial aquele no qual o potencial matricial estivesse o mais próximo da saturação, mas enquanto alguns tensiômetros estavam dando leituras de potencial matricial, outros indicavam potencial de pressão. 

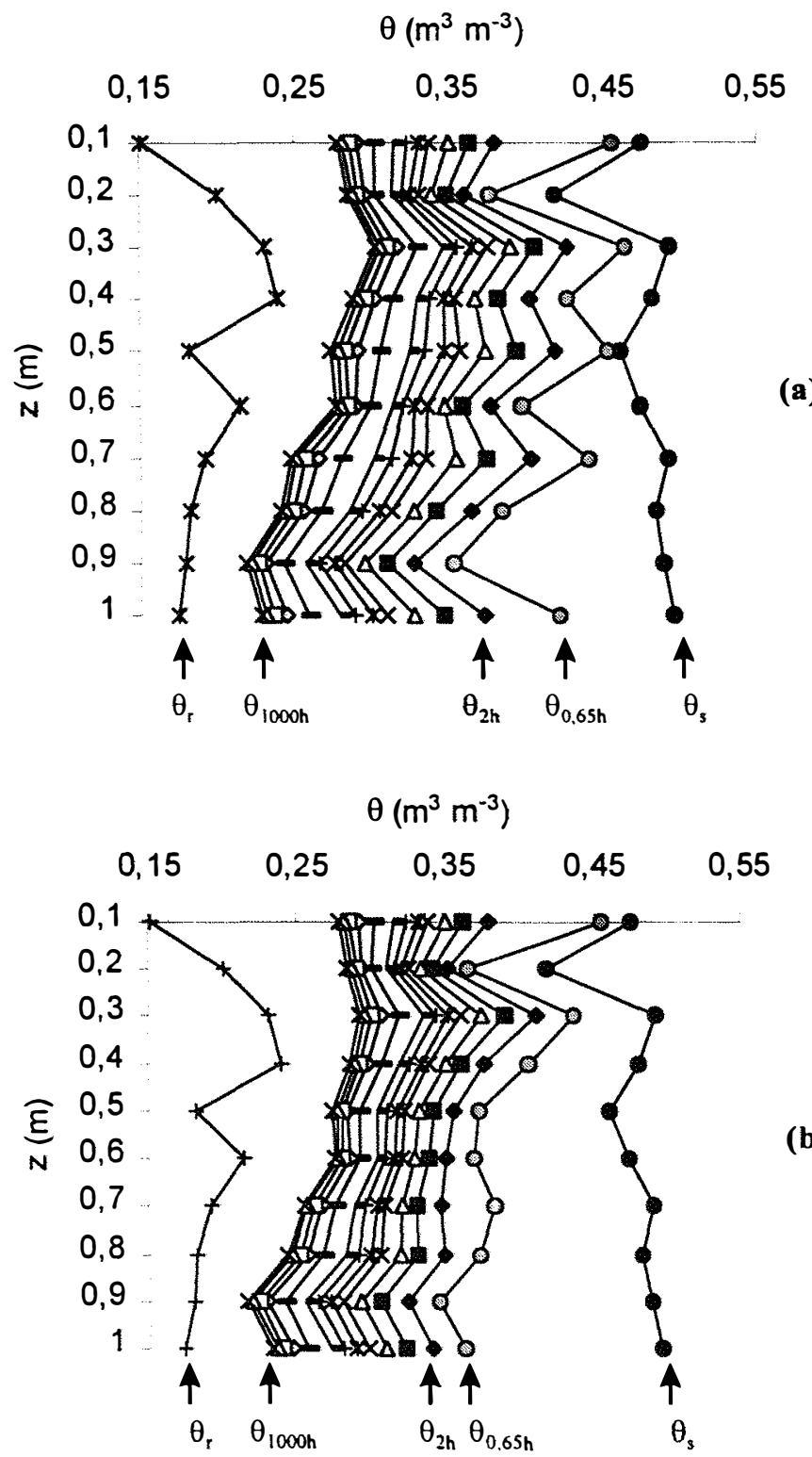

Figura 9. Variação do conteúdo hídrico em profundidade nos diferentes tempos de redistribuição. $\theta_{r}$ e $\theta_{s}$ são os parâmetros de ajuste da equação de van Genuchten (1980). O gráfico apresenta os dados da bateria de tensiômetros da esquerda (a) e da direita (b).

Como a evolução do conteúdo hidrico em função do tempo ajustou-se a uma função de potência do tipo $\theta=b t^{a}$, sendo $t$ tempo e $a$ e $b$ constantes, com $r^{2}>0,91$ em todas as profundidades e para as duas baterias de tensiômetros (Figura 10), tentou-se 
estimar-la a partir da equação de ajuste, mas quando $t=0, \theta_{0}$ se anula, e assim outro tipo de equação poderia ser a solução ao problema.

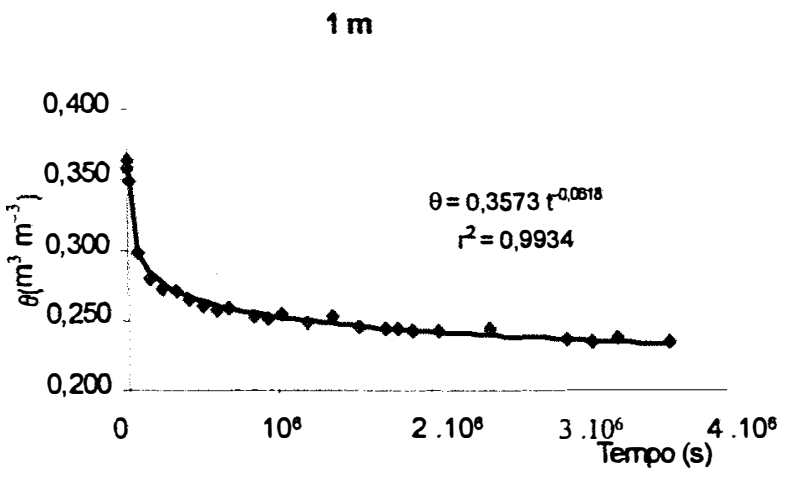

Figura 10. Exemplo do ajuste da umidade volumétrica com o tempo a uma função de potência na camada de $1 \mathrm{~m}$.

A Figura 9 e a Figura 10 apresentam que as variações de umidade volumétrica são cada vez menores com o transcurso do tempo e foram baixas no final da redistribuição. O potencial total apresentou baixas variações no fim da redistribuição sendo as tensões de potencial matricial atingidas entre -12 a $-22 \mathrm{kPa}$ nas duas baterias de tensiômetros em todas as profundidades. Isto confirma a afirmação de Dirksen (1991), de que é dificil atingir valores de potencial matricial superiores a -20 $\mathrm{kPa}$ de tensão com o método da drenagem interna, ficando o solo num conteúdo hídrico que não é próximo a $\theta_{\mathrm{r}}$ (Figura 10).

Uma importante observação que surge das colocações anteriores é que as equações $K=K_{0} \exp \gamma\left(\theta-\theta_{0}\right)$ obtidas para cada profundidade ficam restritas à faixa de utilização devido ao fato de não poderem ser extrapoladas da faixa de umidade em que foram obtidas. Dirksen (1991) apresenta que a faixa de conteúdo hidrico e potencial matricial na qual $K(\theta)$ pode ser determinado é a principal desvantagem do método.

Reichardt et al. (1998) estudando um latossolo vermelho amarelo, substituíram os valores de $\theta_{\circ}$ pelos valores de $\theta$ aos 5 minutos de redistribuição para determinar a influência na determinação dos parâmetros de ajuste, e encontraram que os valores de $\gamma$ não variaram. Discutiram também que os $\theta_{\circ}$ e $K_{0}$ são coeficientes de 
ajuste e cada eleição de $\theta_{0}$ correspondeu a um valor de $K_{0}$. Somente quando $\theta_{0}$ é medido no tempo inicial e corresponde ao conteúdo hidrico de saturação, o valor de $K_{\mathrm{O}}$ tem o significado físico da condutividade hidráulica saturada. O discutido anteriormente indica as dificuldades na estimativa da condutividade hidráulica saturada na faixa perto de saturação, pela metodologia da drenagem interna.

Ao ser a umidade volumétrica $(\theta)$ parte do exponente da equação $K=K_{\mathrm{O}} \exp \chi(\theta$ $\theta_{0}$ ), sua determinação é critica e pequenas variações vão influenciar grandemente a determinação da condutividade hidráulica $(K)$. Segundo Reichardt et al. (1998) pequenas diferenças em $\theta$ causam grandes diferenças de $K$ e $\gamma$ indicando a sensibilidade da inclinação da curva $\theta$ vs. $t$ na estimativa de $K(\theta)$. As leituras nos manômetros de mercúrio foram sensiveis presumivelmente a variações de temperatura como foi mostrado no item 3.2.1 (Material e Métodos), as diferenças de leitura podem influenciar a determinação dos conteúdos hidricos e transmitir assim os erros no cálculo de $K(\theta)$. Dirksen (1991) discute que as medições de potencial hidráulico são relativamente dificeis e podem ser muito imprecisas, agregando que os manômetros de mercúrio tem uma precisão limitada $a \pm 2,5 \mathrm{~cm}$.

Lembrando que $\gamma$ é o exponente da equação de ajuste, pequenas variações em seu valor podem causar grandes variações no valor de $K$. Entre as duas baterias de tensiômetros a maior diferença foi de 1.6 vezes a $0,7 \mathrm{~m}$ de profundidade e a máxima variação dentro do perfil, foi de 2,1 vezes (Tabela 5) quando utilizado o método do perfil instantâneo (Hillel et al., 1972). 
Tabela 5. Parâmetros da função $\mathrm{K}=\mathrm{K}_{0} \times \mathrm{e}^{\gamma\left(\theta-\theta_{0}\right)}$ para cada profundidade obtidos a partir do método de Hillel et al. (1972) em duas baterias de tensiômetros. Os coeficientes de correlação correspondem à regressão $\ln K$ vs. $\theta$.

\begin{tabular}{|c|c|c|c|c|c|c|c|c|}
\hline \multirow{2}{*}{$\begin{array}{l}\text { Prof. } \\
\text { (m) }\end{array}$} & \multicolumn{4}{|c|}{ Esquerda } & \multicolumn{4}{|c|}{ Direita } \\
\hline & $\theta_{0}$ & $\mathrm{~K}_{\mathrm{o}}\left(\mathrm{m} \mathrm{s}^{-1}\right)$ & $\gamma$ & $r^{2}$ & $\theta_{0}$ & $\mathrm{~K}_{\mathrm{o}}\left(\mathrm{m} \mathrm{s}^{-1}\right)$ & $\gamma$ & $r^{2}$ \\
\hline 0.1 & 0.455 & $2.54 .10^{-5}$ & 74,4 & 0.988 & 0,455 & $1,28.10^{-5}$ & 74,2 & 0,986 \\
\hline 0.2 & 0.377 & $5.83 .10^{-7}$ & 99.4 & 0.991 & 0,368 & $2,56.10^{-7}$ & 106,5 & 0,993 \\
\hline 0.3 & 0.464 & $2.17 .10^{-6}$ & 61.4 & 0.989 & 0,436 & $3,56 \cdot 10^{-7}$ & 60,8 & 0,995 \\
\hline 0.4 & 0.426 & $7.61 .10^{-5}$ & 66.6 & 0.992 & 0,406 & $6,67 \cdot 10^{-7}$ & 76,7 & 0,998 \\
\hline 0.5 & 0.452 & $7.94 .10^{-7}$ & 51.3 & 0,993 & 0,373 & $3,00.10^{-7}$ & 82,9 & 0,999 \\
\hline 0,6 & 0.398 & $2.28 \cdot 10^{-6}$ & 72,0 & 0,998 & 0,370 & $4,39 \cdot 10^{-7}$ & 87,2 & 0,999 \\
\hline 0.7 & 0.440 & $8.53 .10^{-7}$ & 45,4 & 0,996 & 0,384 & $2,00.10^{-6}$ & 74,1 & 0,997 \\
\hline 0.8 & 0.384 & $6.67 .10^{-7}$ & 56.6 & 0,996 & 0,374 & $1,04 \cdot 10^{-6}$ & 66,0 & 0,993 \\
\hline 0.9 & 0.353 & $1.73 .10^{-6}$ & 63.8 & 0,995 & 0,346 & $1,38.10^{-6}$ & 66,6 & 0,988 \\
\hline 1 & 0.420 & $2.47 .10^{-4}$ & 48,7 & 0,992 & 0,364 & $2,33 \cdot 10^{-6}$ & 67,8 & 0,984 \\
\hline
\end{tabular}

A partir dos dados da Tabela 5 foram calculadas as condutividades hidráulicas. $K(0,35)$, nas diferentes camadas para a bateria de tensiômetros da direita utilizando um conteúdo hidrico de $0.35 \mathrm{~m}^{3} \mathrm{~m}^{-3}$. Os resultados mostram valores de condutividade hidráulica menores nos primeiros $0,4 \mathrm{~m}$ onde, a densidade média de solo foi $1424 \mathrm{~kg} \mathrm{~m}^{-3}$ e a porosidade total de $0,459 \mathrm{~m}^{3} \mathrm{~m}^{-3}$ contra $1270 \mathrm{~kg} \mathrm{~m}^{-3}$ e $0,520 \mathrm{~m}^{3}$ $\mathrm{m}^{-3}$ nas camadas de 0,5 a $0.9 \mathrm{~m}$ indicando a influência desses parâmetros físicos no comportamento hidráulico. Pode ser observada também uma diferença de 555 vezes entre o menor e o maior valor estimado $(0,4$ e $0,9 \mathrm{~m}$ de profundidade). A camada de 0 a $0.4 \mathrm{~m}$ portanto, poderia estar atuando como um impedimento ao fluxo no perfil estudado. 
Tabela 6. Condutividades hidráulicas, $\mathrm{K}(0,35)$, calculadas para um conteúdo hidrico de $0,35 \mathrm{~m}^{3} \mathrm{~m}^{-3}$ nas diferentes camadas do solo em estudo.

\begin{tabular}{cc} 
Profundidade & $\mathbf{K}(\mathbf{0}, \mathbf{3 5})$ \\
$(\mathbf{m})$ & $\left(\mathbf{m ~ s}^{-1}\right)$ \\
\hline 0,1 & $5,29 \cdot 10^{-9}$ \\
0,2 & $3,76 \cdot 10^{-8}$ \\
0,3 & $1,91 \cdot 10^{-9}$ \\
0,4 & $1,91 \cdot 10^{-9}$ \\
0,5 & $4,46 \cdot 10^{-8}$ \\
0,6 & $7,67 \cdot 10^{-8}$ \\
0,7 & $1,61.10^{-7}$ \\
0,8 & $2,13 \cdot 10^{-7}$ \\
0,9 & $1,06 \cdot 10^{-6}$ \\
1 & $9.02 \cdot 10^{-7}$ \\
\hline
\end{tabular}

Os valores de condutividade hidráulica obtidos experimentalmente em todas as profundidades em diferentes conteúdos hidricos volumétricos são apresentados graficamente na Figura 11. A informação pode ser complementada com os coeficientes de correlação das regressões $\ln K$ vs. $\theta$ (Tabela 5) onde se pode observar uma forte correlação em cada camada de solo. Os dados analisados em conjunto confirmam a falta de homogeneidade do perfil em estudo (item 4.2) e as grandes diferenças de condutividade hidráulica que podem ser obtidas como foi exemplificado na Tabela 6 . Essa falta de homogeneidade tem que manifestar sua influência em variações no potencial matricial do solo em profundidade nos diferentes tempos de redistribuição, isto é, o gradiente de potencial matricial deveria ser diferente de zero. 

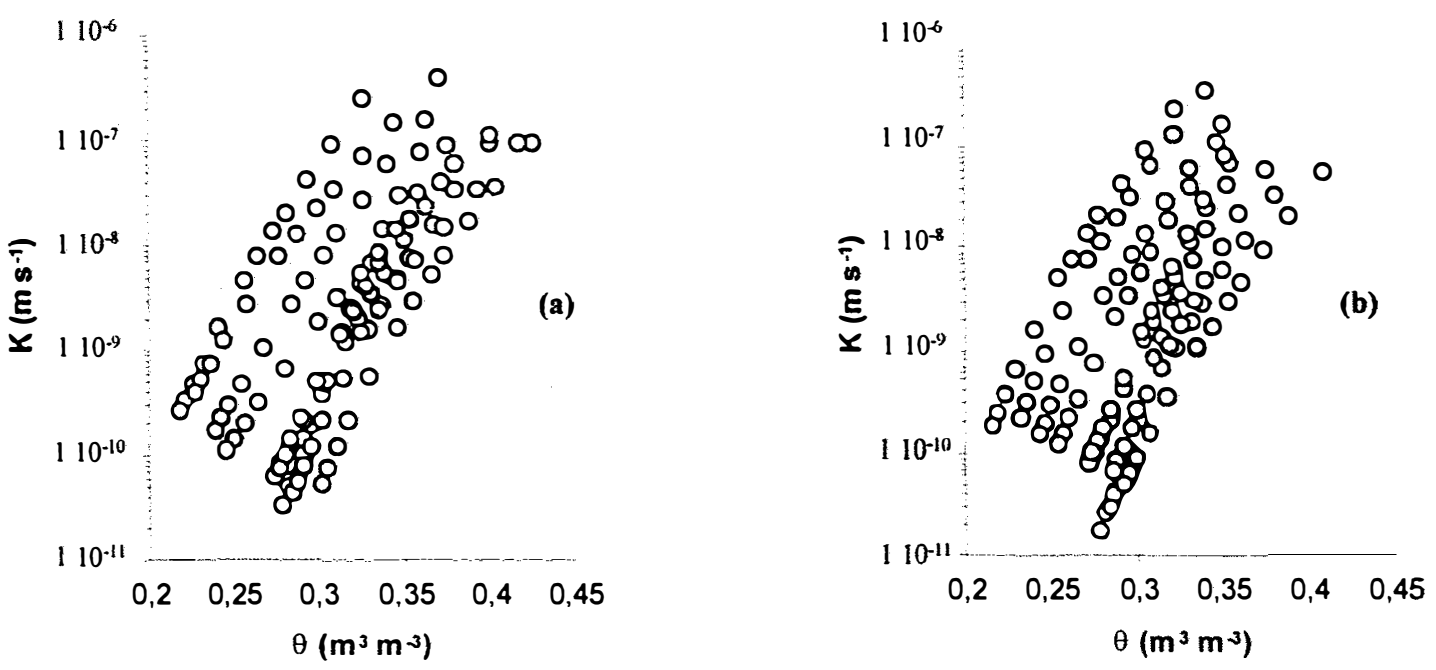

Figura 11. Variação da condutividade hidráulica como a umidade volumétrica correspondentes a todas as camadas do perfil de solo em estudo. (a) bateria de tensiômetros da esquerda e (b) bateria de tensiômetros da direita.

A Figura 12 mostra que o potencial total foi crescente com o acréscimo do tempo de redistribuição e da profundidade. Se o acréscimo de potencial total fosse causado somente por uma variação de potencial gravitacional, as linhas deveriam ser retas paralelas de $45^{\circ}$ de inclinação, mas o potencial matricial teve uma maior diminuição em profundidade que nas camadas superficiais. Por exemplo, o potencial matricial na bateria de tensiômetros da direita às duas horas de redistribuição foi 1,4 $\mathrm{kPa}$ ès mil horas $12,5 \mathrm{kPa}$ na camada de $0,1 \mathrm{~m}$ e na camada correspondente a $1 \mathrm{~m}$ de profundidade foi 4,8 e 22,3 kPa às 2 e 1000 horas respetivamente. O exposto indica que a drenagem nas camadas profundas foi maior e pode ser confirmando pela Tabela 6 que mostra que as condutividades hidráulicas nos primeiros $0,4 \mathrm{~m}$ do perfil de solo foram menores que as restantes, atuando portando como zona de impedimento.

A evolução do potencial total com a profundidade apresentou variações maiores na faixa de 0,4 a 0,7 m (Figura 12) mostrando a influência cada vez maior do potencial matricial especialmente na bateria de tensiômetros da esquerda (a). 0 comportamento do gradiente de potencial total nas camadas mencionadas também pode ser visto na Figura 13. 

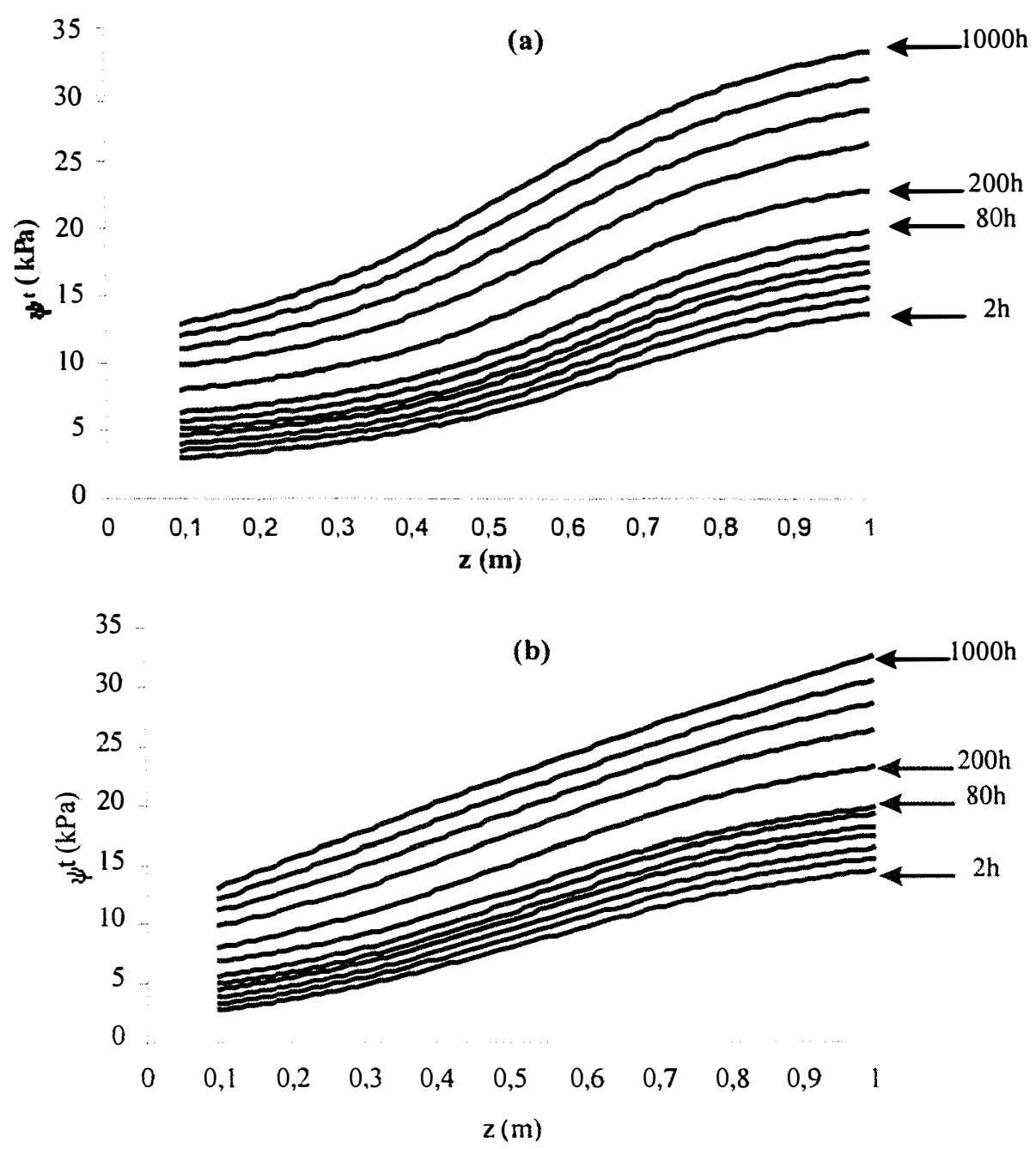

Figura 12. Evolução do valor absoluto de potencial total com a profundidade nos diferentes tempos de redistribuição na bateria de tensiômetros da esquerda (a) e da direita (b).

Além do gradiente de potencial total mostrar um maior acréscimo nas camadas de 0,4 a $0,7 \mathrm{~m}$, a Figura 13 mostra que $\circ$ foi crescente com o tempo nas duas baterias de tensiômetros e em todas as profundidades. Em quase todas as camadas foi maior que a unidade chegando próximo a 3,5 nas camadas de 0,5 e 0,6 $\mathrm{m}$. Nos casos que o gradiente esteve perto da unidade, foi até aproximadamente 10 dias depois de começada a infiltração. Os gradientes hidráulicos são influenciados geralmente, pela natureza e complexidade do solo variando com o tempo (diminuição 
da umidade e portanto do potencial matricial) e profundidade (Ahuja et al., 1988; Chong et al., 1981).
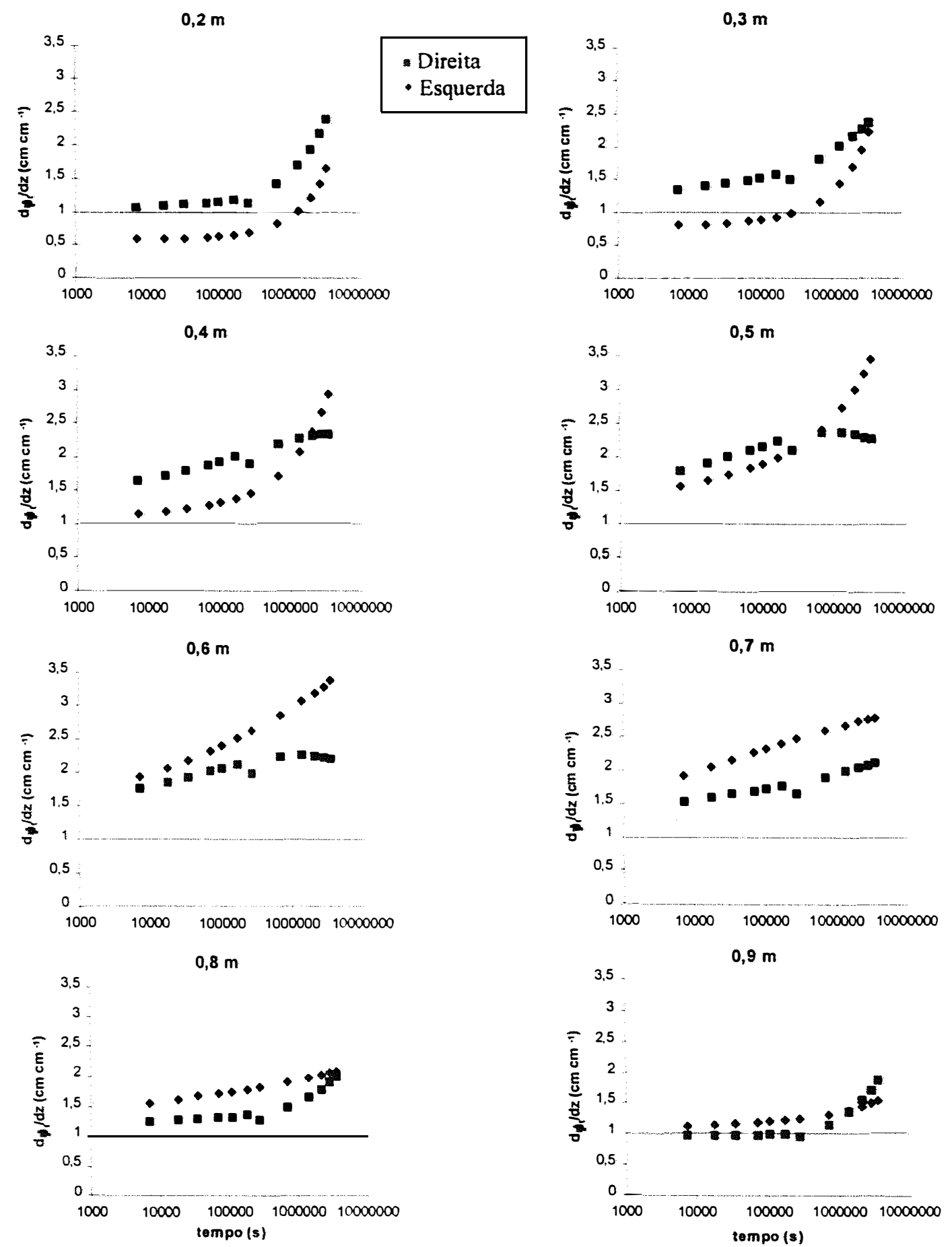

Figura 13. Evolução do gradiente hidráulico com o tempo no perfil do solo. 
$\dot{E}$ de esperar então que as metodologias que têm assumido o gradiente unitário comecem a apresentar erros mais importantes a partir dos 10 a 15 dias após iniciada a redistribuição o que coincidente com o apresentado por (Dirksen, 1991; Bacchi \& Reichardt, 1993), que mostra que os erros mais importantes encontram-se na faixa seca que por sua vez se propagam logo no cálculo de $K(\theta)$.

Davidson (1969) apresentou que para um perfil de solo uniforme a variação de conteúdo hídrico ou de potencial matricial com a profundidade deveria ser pequeno e poderia ser assumido nulo sem erros apreciáveis e que em tais condições a água deveria drenar igualmente em todas as profundidades. Ao assumir que o gradiente de potencial total é unitário, a variação de potencial matricial com a profundidade com um determinado tempo de redistribuição tem que ser nula com o que o fluxo é igual à condutividade hidráulica. Como foi mostrado anteriormente, o gradiente foi superior à unidade em varias ocasiões, Figura 13, contrariando 0 pressuposto de homogeneidade. Isto também quer dizer que nos métodos da umidade e do fluxo é de se esperar superestimativas da condutividade hidráulica (eq. 11, pág. 11).

A colocação apresentada por Davidson (1969) foi refutada por Reichardt (1993) quem afirmou que o pressuposto de gradiente unitário contém contradições que podem ser demostradas teoricamente: "gradientes unitários de potencial hidráulico da água não podem ocorrer em perfis homogêneos de solo sob drenagem interna, apesar desta aproximação ter sido utilizada com sucesso em vários métodos de determinação de condutividade hidráulica do solo" sendo esta outra das desvantagens ao assumir este pressuposto.

Outra das condições necessárias para que o raciocinio das metodologias da umidade e do fluxo sejam válidas é que a translação dos perfis de umidade seja paralela em relação ao perfil inicial. Como foi observado na Figura 9, nas duas baterias de tensiômetros foi registrado esse comportamento sendo favorável na aplicação das metodologias que assumem o gradiente unitário.

A Tabela 7 e Tabela 8 mostram os parâmetros da função $K=K_{0} \exp \left\{\left(\theta-\theta_{0}\right)\right.$ obtidos a partir dos datos coletados na bateria de tensiômetros da esquerda e direita 
calculados utilizando-se as metodologias da umidade e do fluxo (Libardi et al., 1980). Pode-se observar que os valores de $K_{O}$ e $\gamma$ são sempre maiores quando calculados pelo método da umidade. Como no cálculo o valor de $\theta_{0}$ é igual em ambas metodologias, as estimativas de condutividade hidráulica deverão ser maiores pelo método da umidade. Outra das diferenças dos métodos é que ao contrário da eq. 12, a eq. 14 (pág. 13 respectivamente), permanece válida para todos os tempos, mas tem a desvantagem de conter $d \bar{\theta} / d t$ ao invés de $\theta$ o que pode acarretar mais erros em dados espalhados de campo (Libardi, 1995). A afirmação é corroborada ao observar que os coeficientes de correlação calculados a partir das regressões feitas para estimar $K_{O}$ e $\gamma$ no método da umidade são maiores que os calculados para o método do fluxo (Tabela 7 Tabela 8).

Tabela 7. Parâmetros da função $\mathrm{K}=\mathrm{K}_{0} \times \mathrm{e}^{\gamma\left(\theta-\theta_{11}\right)}$ para cada profundidade obtidas a partir do método da umidade de Libardi et al. (1980) em duas baterias de tensiômetros.

\begin{tabular}{|c|c|c|c|c|c|c|c|c|}
\hline \multirow{2}{*}{$\begin{array}{l}\text { Prof. } \\
(\mathbf{m})\end{array}$} & \multicolumn{4}{|c|}{ Esquerda } & \multicolumn{4}{|c|}{ Direita } \\
\hline & $\theta_{0}$ & $K_{o}\left(m^{-1}\right)$ & $\gamma$ & $r^{2}$ & $\theta_{0}$ & $K_{0}\left(m ~ s^{-1}\right)$ & $\gamma$ & $r^{2}$ \\
\hline 0.1 & 0.455 & $+.97 .10^{-5}$ & 87.7 & 0.932 & 0.455 & $4,97 \cdot 10^{-5}$ & 87,7 & 0,932 \\
\hline 0.2 & 0.377 & $1.39 .10^{-6}$ & 85.5 & 0,985 & 0.368 & $1,39.10^{-6}$ & 94,3 & 0,966 \\
\hline 0.3 & $0.46 t$ & $9.17 .10^{-6}$ & 57.5 & 0.978 & 0.436 & $7,5.10^{-6}$ & 66,7 & 0,876 \\
\hline 0.4 & 0.426 & $8.06 \cdot 10^{-6}$ & 66.2 & 0,974 & 0,406 & $2,42.10^{-5}$ & 111,1 & 0,879 \\
\hline 0.5 & 0.452 & $3.03 .10^{-5}$ & 69.0 & 0,984 & 0.373 & $4,44 \cdot 10^{-6}$ & 81,3 & 0,994 \\
\hline 0.6 & 0.398 & $7.5 .10^{-6}$ & 69.0 & 0,936 & 0.370 & $5,83 \cdot 10^{-6}$ & 86,2 & 0,964 \\
\hline 0.7 & 0.440 & $7.06 .10^{-5}$ & 81.3 & 0,967 & 0.384 & $2,67.10^{-5}$ & 78,7 & 0,977 \\
\hline 0.8 & 0.384 & $1.06 .10^{-5}$ & 57.1 & 0,989 & 0.374 & $2,14 \cdot 10^{-5}$ & 79,4 & 0,934 \\
\hline 0.9 & 0.353 & $2.03 .10^{-5}$ & 69.9 & 0,996 & 0,346 & $1,25.10^{-5}$ & 65,4 & 0,986 \\
\hline 1 & 0.420 & $9.61 .10^{-5}$ & 66.7 & 0,987 & 0.364 & $1,89 \cdot 10^{-5}$ & 70,9 & 0,977 \\
\hline
\end{tabular}


Tabela 8. Parâmetros da função $\mathrm{K}=\mathrm{K}_{0} \times \mathrm{e}^{\gamma\left(\theta-\theta_{1}\right)}$ para cada profundidade obtidas a partir do método do fluxo de Libardi et al. (1980) em duas baterias de tensiômetros.

\begin{tabular}{|c|c|c|c|c|c|c|c|c|}
\hline \multirow{2}{*}{$\begin{array}{l}\text { Prof. } \\
\text { (m) }\end{array}$} & \multicolumn{4}{|c|}{ Esquerda } & \multicolumn{4}{|c|}{ Direita } \\
\hline & $\theta_{0}$ & $K_{o}\left(\mathrm{~m} \mathrm{~s}^{-1}\right)$ & $\gamma$ & $\mathbf{r}^{2}$ & $\theta_{0}$ & $\mathbf{K}_{0}\left(\mathrm{~m} \mathrm{~s}^{-1}\right)$ & $\gamma$ & $r^{2}$ \\
\hline 0.1 & 0,455 & $2,85.10^{-5}$ & 63,0 & 0,981 & 0,455 & $2,85.10^{-5}$ & 63,0 & 0,981 \\
\hline 0,2 & 0,377 & $1.11 .10^{-7}$ & 28,1 & 0,861 & 0,368 & $4,44 \cdot 10^{-7}$ & 78,0 & 0,959 \\
\hline 0.3 & 0.464 & $3,22 \cdot 10^{-6}$ & 46,4 & 0,960 & 0,436 & $1,50.10^{-6}$ & 47,3 & 0,939 \\
\hline 0,4 & 0.426 & $2.19 .10^{-6}$ & 50.1 & 0,952 & 0,406 & $4,47 \cdot 10^{-6}$ & 66,4 & 0,956 \\
\hline 0,5 & 0,452 & $2,88 \cdot 10^{-6}$ & 37,1 & 0,882 & 0,373 & $1,33.10^{-6}$ & 65,7 & 0,951 \\
\hline 0,6 & 0,398 & $2,28.10^{-6}$ & 55,2 & 0,949 & 0,370 & $1,72 \cdot 10^{-6}$ & 68,6 & 0,953 \\
\hline 0,7 & 0.440 & $4,44 \cdot 10^{-6}$ & 34,1 & 0,845 & 0,384 & $9,83 \cdot 10^{-6}$ & 62,4 & 0,967 \\
\hline 0.8 & 0,384 & $1.81 .10^{-6}$ & 39,5 & 0.877 & 0,374 & $3,47.10^{-6}$ & 50,9 & 0,926 \\
\hline 0,9 & 0,353 & $4,11.10^{-6}$ & 49,6 & 0,931 & 0,346 & $2,89 \cdot 10^{-6}$ & 48,9 & 0,927 \\
\hline 1 & 0,420 & $2,67.10^{-6}$ & 16,5 & 0,916 & 0,364 & $3,86.10^{-6}$ & 49,7 & 0,930 \\
\hline
\end{tabular}

\subsubsection{Infiltrômetro de tensão}

Houve dificuldades na coleta dos dados no campo causadas pelas caracteristicas do infiltrômetro que se traduziram na presença de dispersão nos dados de fluxo. No Apêndice 1, são apresentados graficamente exemplos de dispersão dos dados originados nas dificuldades experimentais relatadas a seguir.

A dificuldade na coleta dos dados foi crescente com a diminuição da tensão pois esta é acompanhada por um aumento do fluxo, levando a um aumento na freqüência de leituras. Foi notada uma maior dificuldade quando as leituras estavam espaçadas por intervalos de tempo menores que 30 segundos e os erros se originaram principalmente da interferência das bolhas de ar produzidas pelo aparelho com a escala de leitura. Quando ocorreram fluxos da ordem de grandeza de $10^{-7} \mathrm{~m} \mathrm{~s}^{-1}$ ou menores, o espaçamento entre leituras teve que ser aumentado para poder detectar diferenças entre leituras consecutivas. Nestes casos o maior problema não foi 
a interferência da bolhas de ar, mais sim, não perceber visualmente diferenças na escala de medida.

A presença de dados dispersos se traduz logo em dificuldades na manipulação e uso dos mesmos. O principal inconveniente foi na determinação do fluxo estacionário, $q_{x}$, um dos principais parâmetros nas equações que são utilizadas para calcular a condutividade hidráulica e a sortividade. Também pode ocasionar problemas no ajuste de uma função que permita interpolar a taxa de infiltração para diferentes tempos.

A coleta automatizada de dados permitiria um melhor controle especialmente em tensões baixas. medições em intervalos de tempo curtos, melhora na precisão das medições em baixas taxas de fluxo, e eliminar a variabilidade induzida pelo borbulhamento, além de permitir, um manejo e análise dos dados mais eficiente (Ankeny et al., 1988).

Apesar dos inconvenientes mencionados, a infiltração acumulada em função do tempo pode ser obtida para cada tensão. A maior dificuldade é a obtenção da umidade antecedente ao ensaio levando-se em consideração que não pode-se retirar amostras entre medições por terem sido feitas as quatro tensões de cada repetição (1; $0,5 ; 0,25 ; 0 \mathrm{kPa})$ no mesmo local

A Tabela 9 apresenta os resultados obtidos utilizando a metodologia de Ankeny et al. (1991) (Anexo 1) para infiltrômetros de bases diferentes. As condutividades hidráulicas foram maiores com o infiltrômetro de raio menor exceto para $0 \mathrm{kPa}$ de tensão. Os resultados são coerentes levando em consideração que com o raio menor é proporcionalmente maior a superfície na que pode infiltrar a água. Analisando um mesmo infiltrômetro, a condutividade hidráulica foi crescente com a diminuição da tensão devido a que poros maiores estão conduzindo água. 
Tabela 9. Condutividade hidráulica obtida pelo método de Ankeny et al. (1991)

\begin{tabular}{|c|c|c|c|c|}
\hline \multirow{2}{*}{$\begin{array}{c}\text { Conductividade } \\
\text { Hidráulica } \\
\end{array}$} & \multicolumn{3}{|c|}{ Tensão } & \multirow[b]{2}{*}{$0 \mathrm{kPa}$} \\
\hline & $1 \mathrm{kPa}$ & $0,5 \mathrm{kPa}$ & $0,25 \mathrm{kPa}$ & \\
\hline & \multicolumn{4}{|c|}{ raio: $0,113 \mathrm{~m}$} \\
\hline$K\left(\mathrm{~m} \mathrm{~s}^{-1}\right)$ & $7,78 \cdot 10^{-7}$ & $1,19.10^{-6}$ & $2,19.10^{-6}$ & $5,06 \cdot 10^{-6}$ \\
\hline \multirow[t]{2}{*}{ C.V. $(\%)$} & 21,4 & 34,5 & 37,3 & 23,5 \\
\hline & \multicolumn{4}{|c|}{ raio: $0,038 \mathrm{~m}$} \\
\hline$K\left(\mathrm{~m} \mathrm{~s}^{-1}\right)$ & $1,22.10^{-6}$ & $1,94 \cdot 10^{-6}$ & $2,94 \cdot 10^{-6}$ & $4,58.10^{-6}$ \\
\hline C.V. $(\%)$ & 8,2 & 33,8 & 53,3 & 68,5 \\
\hline
\end{tabular}

Os valores são médias de quatro repetições. C.V.: coeficiente de variação.

Os coeficientes de variação foram crescentes com a diminuição da tensão para ambos raios exceto no infiltrômetro de raio maior a $0 \mathrm{kPa}$ de tensão. A grandeza da variabilidade das propriedades na superfície do solo próximo a saturação poderia ser atribuida a padrões de fluxo preferencial (White et al., 1992) e lógico esperar que seja crescente com o decréscimo da tensão. Ankeny et al. (1990), Dunn \& Phillips (1991), e White \& Sully (1992) apresentaram C.V. menores que 50\% para condutividades hidráulicas medidas com infiltrômetros de tensão. $O$ grau de variabilidade observado nas medições de campo depende da variabilidade inerente da propriedade, da escala na qual a medição é feita e da natureza da técnica de medição por si mesma (Warrick \& Nielsen, 1980).

A Tabela 10 mostra os resultados obtidos pelo método de Scotter et al. (1982). Os dados correspondem apenas a uma repetição uma vez que outras apresentaram valores negativos de condutividade hidráulica. O trabalho de Logdson \& Jaynes (1993) discute resultados similares, argumentando que o método é sensivel às variações espaciais das propriedades hidráulicas ao utilizar dois raios. Elrick \& Reinolds (1992) argumentam que todas as metodologias são afetadas pela heterogeneidade do solo, mas que os procedimentos que utilizam infiltrômetros de diferentes raios são mais susceptíveis e podem resultar em valores negativos de condutividade hidráulica e de potencial de fluxo mátrico (resultados obtidos mas não apresentados no trabalho). 
Tabela 10. Condutividade hidráulica em diferentes tensões calculadas utilizando a metodologia de Scotter et al. (1982)

\begin{tabular}{cccccc}
\hline $\begin{array}{c}\text { Tensão } \\
(\mathrm{kPa})\end{array}$ & $\begin{array}{c}\theta_{\mathrm{n}} \\
\left(\mathrm{m}^{3} \mathrm{~m}^{-3}\right)\end{array}$ & $\begin{array}{c}\theta_{0} \\
\left(\mathrm{~m}^{3} \mathrm{~m}^{-3}\right)\end{array}$ & $\begin{array}{c}K_{\mathrm{O}} \\
\left(\mathrm{m} \mathrm{s}^{-1}\right)\end{array}$ & $\begin{array}{c}\mathrm{S}_{\mathrm{O}}^{2} \\
\left(\mathrm{~m}^{2} \mathrm{~h}^{-1}\right)\end{array}$ & $\begin{array}{c}t_{\text {grav }} \\
\mathrm{h}\end{array}$ \\
\hline 10 & 0,236 & 0,2479 & $1,14.10^{-6}$ & 0,112 & 0,662 \\
5 & 0,236 & 0,2623 & $8,33.10^{-7}$ & 0,449 & 4,894 \\
2.5 & 0,236 & 0,2778 & $2,14.10^{-6}$ & 0,693 & 1,158 \\
0 & 0,236 & 0,4750 & $2,47.10^{-6}$ & 7,417 & 9,343 \\
\hline
\end{tabular}

$\theta_{n}$ : conteúdo hídrico volumétrico inicial: $\theta_{0}$ : conteúdo hídrico volumétrico final: $K_{\mathrm{O}}$ : condutividade hidráulica; $\mathrm{S}_{\mathrm{O}}$ : sortividade e $t_{\text {grav }}$ : tempo gravimétrico.

Scotter et al. (1982) mostra que para que a metodologia dê resultados razoáveis o raio do infiltrômetro maior tem que ser no minimo duas vezes o tamanho do menor, $r_{1}>2 r_{2}$, e que o valor de $C_{k}$ calculado a partir da eq. 27 (pág. 16) seja maior que 0,3. A primeira condição foi cumprida levando em consideração os raios dos infiltrômetros utilizados no experimento, e o valor de $C_{k}$ foi maior que 0,3 somente na repetição onde não se obtiveram resultados negativos de condutividade hidráulica.

A principal dificuldade na estimativa da sortividade utilizando a eq. A21, pág. 67 foi a obtenção do conteúdo hidrico final, $\theta_{0}$. Ao serem realizadas as medições das quatro tensões $(1 ; 0.5 ; 0,25 ; 0 \mathrm{kPa})$ de cada repetição no mesmo local não foi possivel retirar amostras para se obter pelo método gravimétrico o conteúdo hidrico final correspondente a cada tensão. Por tais motivos, o conteúdo hídrico foi extrapolado da curva de retenção o que a rigor seria errôneo para tensões menores a 0,5 kPa por ser este valor a menor tensão medido quando foi confeccionada a curva de retenção.

A sortividade poderia ser obtida também a partir da eq. 22 (pág. 16) mas a camada de areia interfere no fluxo no começo da infiltração até a água atingir o solo (Perroux \& White, 1988) alterando a medida da sortividade. Uma solução alternativa à proposta por Cook \& Broeren (1994) que calculam $\mathrm{S}_{0}$ utilizando a 0 gráfico I vs $\mathrm{t}^{1 / 2}$. Para o cálculo, dividem o gráfico visualmente em três regiões, uma onde se produz a absorção da camada de areia; a segunda onde a sortividade domina o fluxo, sendo calculada a partir da inclinação da reta de ajuste desta região; e a terceira onde a 
geometria começa a influenciar o fluxo. A utilização da metodologia é difícil, especialmente quando se tem dados dispersos, levando-se em consideração que a escolha de cada periodo é arbitrária.

Os tempos gravimétricos calculados foram maiores que os utilizados experimentalmente nas tensões de 0 e $5 \mathrm{kPa}$, mas esses valores foram calculados utilizando-se a sortividade que apresentou problemas na determinação e correspondem a uma repetição, sendo portanto questionável sua validade.

\subsection{Comparação das metodologias utilizadas}

As diferentes técnicas apresentaram diferenças no valor de $K_{\text {Sat }}$ que são o reflexo de limitações experimentais e dos pressupostos assumidos, volume da amostra, grau de perturbação no sistema poroso, diferenças impostas nas condições de contorno, e nos padrões de fluxo uni ou multidimensional (Mohanty et al., 1998).

A Figura 14 mostra que, os maiores valores de condutividade hidráulica foram obtidos com o permeâmetro de carga constante em laboratório, onde pode ser observada uma diferença de aproximadamente 10 vezes em relação a condutividade hidráulica calculada a partir do método de Ankeny et al. (1991) medida com o infiltrômetro de tensão. Uma das possiveis explicações deve-se à condução de água pelos macroporos pois em condições de laboratório, dados os cuidados mencionados no item 3.1, é de esperar que uma maior quantidade de ar aprisonado seja removido na saturação da amostra (Mohanty, 1994). Faybichenco (1995) mostrou que com saturações ascendentes pode-se obter valores da ordem de $2 \%$ de ar aprisionado, valor bem menor que a faixa de 70 a $90 \%$ de saturação obtida com o método da drenagem interna.

Utilizando os dados obtidos para o infiltrômetro de raio maior (Tabela 9) e a equação de Kelvin ${ }^{2}$, se o fluxo à tensão de $0 \mathrm{kPa}$ eqüivale a $100 \%$, os poros de diâmetro equivalente entre 0 e $5 \mathrm{kPa}$ conduzem $76 \%$ da água e representam $9 \%$ do

$$
2 r=\frac{2 \sigma \cos \alpha}{\rho g \tau}=\frac{20.072 \mathrm{Nm}^{-1}}{1000 \mathrm{~kg} \mathrm{m^{-3 }} 9.8 \mathrm{~ms}^{-2} \tau}
$$


volume poroso. O diâmetro equivalente de poros de $5 \mathrm{kPa}$ é $294 \mu \mathrm{m}$ correspondendo à faixa de poros classificada segundo Libardi (1995) como macroporos e tendo eles a função principal de infiltração da água. Outros autores discutem a importância do fluxo pelos macroporos relacionados com a afirmação apresentada. Watson \& Luxmoore (1986) e Wilson \& Luxmoore (1988) quantificaram o fluxo de água em perfis de solos de floresta usando infiltrômetros de tensão. Os primeiros mostraram que $73 \%$ do fluxo da água ocorreu através de macroporos maiores que $1 \mathrm{~mm}$ de diâmetro equivalente $e$ estimaram que $96 \%$ do fluxo foi transmitido através de $0,32 \%$ do volume de solo. Wilson \& Luxmoore (1988) reportaram que $85 \%$ da água foi conduzida por macroporos. Dunn \& Phillip (1991) apresentaram que mais de $70 \%$ do fluxo era conduzido com tensões de $0,06 \mathrm{kPa}$. Os resultados apresentados reforçam a importância da quantificação correta do fluxo próximo a saturação quando é estudado o processo de infiltração de água no solo.

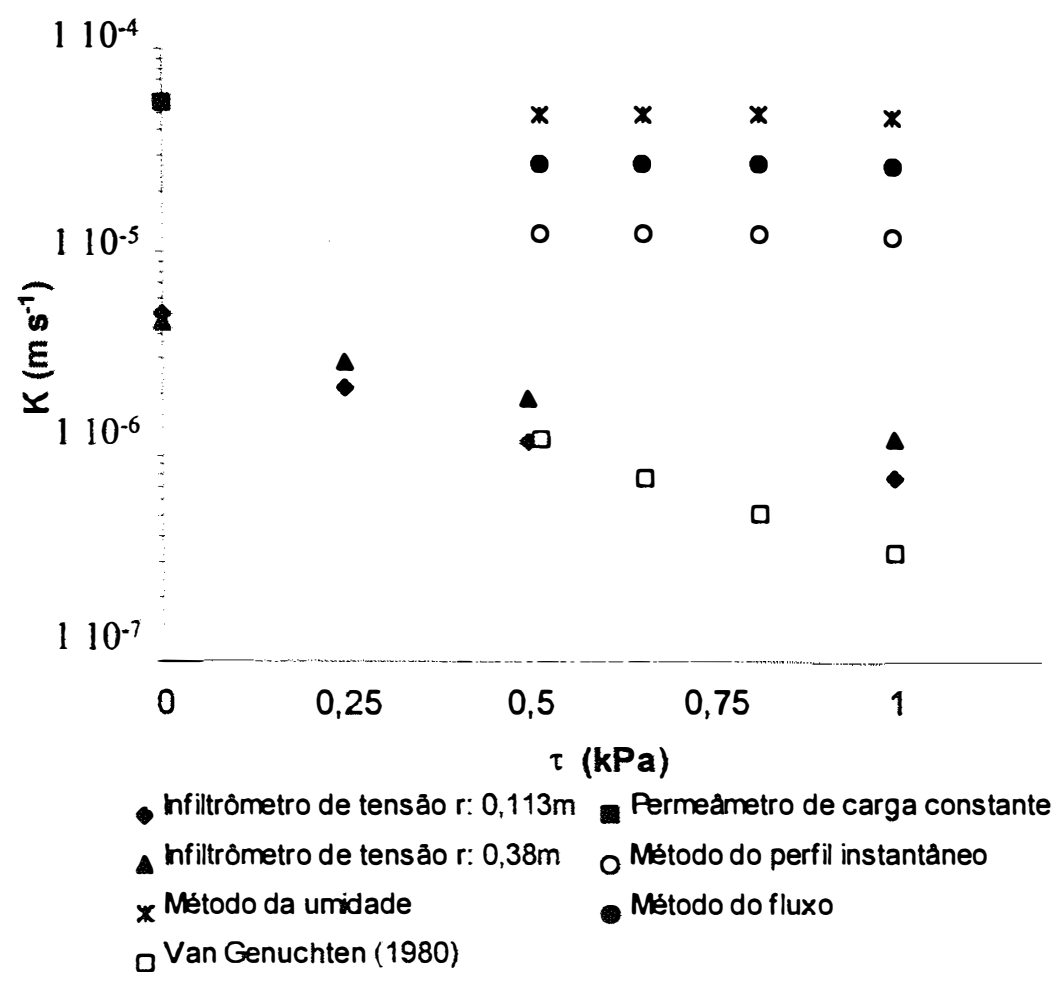

Figura 14. Condutividades hidráulicas obtidas pelos diferentes métodos. 
A condutividade hidráulica relativa derivada da curva de retenção teve a vantagem de dar resultados numa ampla faixa de tensões $(0,5$ a $1500 \mathrm{kPa})$ não conseguidas pelos métodos da drenagem interna (5 a aproximadamente 12 a $25 \mathrm{kPa}$ dependendo da profundidade) e o infiltrômetro de tensão ( 0 a $1 \mathrm{kPa}$ ), mas sua determinação é problemática próxima a saturação. $O$ equipamento necessário é caro e o tempo para obter os resultados foi de quarenta dias, além do tempo utilizado no ajuste dos dados. Outro problema foi escolher $o$ valor de $K_{0}$ que permita fazer os cálculos de $K(\theta)$ (eq. 10, pág. 11) assim, os resultados serão diferentes se for utilizado o valor obtido do permeâmetro de carga constante ou do infiltrômetro de tensão.

No método da drenagem interna foi trabalhosa a instalação do experimento, requerendo grandes volumes de água, leituras dos tensiômetros por aproximadamente quarenta dias e muito tempo para o processamento e análise de dados, sendo por tais motivos dificultoso fazer repetições.

A Figura 14 mostra que as três metodologias de cálculo utilizadas no método da drenagem interna super estimaram as condutividades hidráulicas em relação ao infiltrômetro de tensão na camada de 0,1 m possivelmente porque 0 infiltrômetro de tensão refletiu a maior densidade do solo e menor porosidade total. Como era de se esperar os métodos que têm assumido gradiente unitário apresentaram valores maiores que o método do perfil instantâneo e o método da umidade foi maior que o do fluxo como foi discutido no item. 4.2.1.

Assumir que o gradiente é unitário na tentativa de fazer simplificações pode ser um pressuposto muito forte. Sua conveniência foi argumentada em casos em que se tem que fazer muitas medições devido à grande variabilidade espacial consumindo grande quantidade de tempo experimental e de cálculo (Schuh et al., 1983). Deve-se levar em conta que: (i) em geral, a exatidão da estimativa das propriedades hidráulicas medidas no campo incrementa-se quando o número de simplificações assumidas decresce (Kutilek \& Nielsen, 1994), (ii) ao assumir a hipótese de gradiente unitário foi eliminada a variabilidade vertical causada pela heterogeneidade do solo, e que (iii) com o avanço computacional o processamento é mais simples; questionando a validade dos argumentos apresentados. As considerações feitas não implicam descartar a 
metodologia porque pode ser utilizada em casos particulares onde o pressuposto de homogeneidade pode ser aplicado e porque é evidente que o trabalho se minimiza ao ter que se fazer medições só de evolução do conteúdo hídrico no tempo, podendo ser determinado em casos de falta de instrumental pelo método gravimétrico.

Quando se fazem simplificações de metodologias gerais, em geral funcionam para o caso particular para o qual foram estabelecidas, mas não há garantia que com outro método mais simples não se consigam iguais resultados que uma simplificação de um método mais complexo.

O infiltrômetro de tensão baseado em padrões de fluxo tridimensional refletiu as condições naturais, foi de fácil operação e as perturbações do local foram mínimas durante as medições dando à técnica vantagens adicionais sobre as outras. Ainda, pode ser uma ferramenta útil para a quantificação do efeito dos macroporos na infiltração no campo como foi discutido anteriormente (Everts \& Kanwar, 1993). Como o aparelho é facilmente transportável e requer pouca quantidade de água, é praticável a realização de maior número de determinações e também é possível utiliza-lo em lugares onde a disponibilidade de água é limitada. Um dos problemas detectado com o infiltrômetro foi a não existência de uma metodologia de cálculo nem de utilização que seja padrão, tendo-se que adaptar a cada solo estudado. Por outro lado, a informação se encontra dispersa em inúmeros artigos científicos e também é grande o desenvolvimento matemático relativo ao assunto sendo importante conhecê-lo para saber quais as vantagens e desvantagens de cada metodologia.

A escolha de um método para a determinação das propriedades hidráulicas depende portanto: (i) da escala de medida desejada, (ii) do local e das condições de solo a serem caraterizadas, (iii) da disponibilidade de tempo e recursos, (iv) da exatidão requerida pela medida (Paige \& Hillel, 1993; Gupta et al., 1993) podendo ser necessário o uso de mais de um para garantir descrição adequada da dinâmica do fluxo de água no solo. Os métodos de van Genuchten (1980) e da drenagem interna (Hillel et al., 1972; Libardi et al., 1980) apresentaram problemas na determinação da contutividade hidráulica em tensões baixas pelas dificuldades que ocorrem ao medir-se o fluxo próximo a saturação, e poderiam ser combinados com medidas mais confiáveis 
feitas com infiltrômetros de tensão. mas quando a matriz domina as propriedades hidráulicas são mais facilmente medidas pelos primeiros.

Outro importante problema é a representatividade da amostra. É mais representativa a cápsula de um tensiômetro instalada numa camada ou uma amostra que logo é processada em condições melhor controladas no laboratório? Deve ser feita a colocação da importância das funções de pedo transferência (pedotransfer functions) que permitiriam a partir de propriedades de fácil medição fazer correlações com propriedades hidráulicas mais complexas.

Os resultados demostram a necessidade de medições das propriedades hidráulicas do solo simples e confiáveis em sua estimação ou predição (Clothier \& Smettem, 1990), surgindo a questão de como diferentes valores dos parâmetros podem influenciar as estimações de fluxo de água ou transporte de solutos quando usadas num modelo de infiltração. 


\title{
5. CONCLUSÃO
}

\begin{abstract}
Pela simplicidade do instrumental e da infra-estrutura necessárias, pela possibilidade de ampliar-se $o$ número de repetições e assim contemplar-se a variabilidade espacial e temporal das propriedades hídricas do solo, o infiltrômetro de tensão mostrou-se uma ferramenta satisfatória para o levantamento dos parâmetros dos modelos de infiltração analisados.
\end{abstract}


ANEXO 1 
1 Determinação da Condutividade hidráulica utilizando um infiltrômetro de disco de raio $r$ sob duas tensões $\left(\tau_{1}\right.$ e $\left.\tau_{2}\right)$

Ankeny et al. (1991) propuseram uma metodología para cálculo da condutividade hidráulica a partir dos valores de fluxo estacionário da infiltração tridimensional medida com $\circ$ infiltrômetro de tensão, obtidos para dois diferentes valores de potencial mátrico ou tensão de água no solo $(\tau)$. A metodologia é baseada na expressão simplificada proposta por Wooding (1968) :

$$
\mathrm{q}=\mathrm{K}_{0}+\frac{4 \phi_{0}}{\pi \mathrm{r}}
$$

onde:

q: fluxo estacionário

$K_{0}$ : condutividade hidráulica

r: raio da base do infiltrômetro

$\phi_{0}:$ potencial de fluxo mátrico

O potencial de fluxo mátrico foi definido por Raats \& Gardner (1971) como:

$$
\phi=\int_{\tau_{i}}^{\tau_{r}} K(\tau) \mathrm{d} \tau
$$

onde:

$\tau_{i:}$ tensão inicial

$\tau_{f}$ : tensão utilizada no infiltrômetro

Para $\tau_{\mathrm{f}}=\tau_{1}$ e $\tau_{\mathrm{f}}=\tau_{2}$, sendo $\tau_{1} \neq \tau_{2}$, as medidas de fluxo estacionário, $\mathrm{q}_{1}$ e $\mathrm{q}_{2}$, serão diferentes. Considerando o raio do infiltrômetro $r$ os fluxos ficam definidos por:

$$
\mathrm{q}_{1}=\mathrm{K}_{1}+\frac{4 \phi_{1}}{\pi \mathrm{r}}
$$




$$
\mathrm{q}_{2}=\mathrm{K}_{2}+\frac{4 \phi_{2}}{\pi \mathrm{r}}
$$

Estas duas equaçōes possuem quatro incógnitas $\left(K_{1}, \phi_{1}, K_{2}\right.$, e $\left.\phi_{2}\right)$. Ankeny et al. (1991) assumiram a relação $\mathrm{K} / \phi$ constante entre $\tau_{1}$ e $\tau_{2}$. Assim:

$$
\begin{aligned}
& \frac{\mathrm{K}_{1}}{\phi_{1}}=\alpha \Rightarrow \phi_{1}=\frac{\mathrm{K}_{1}}{\alpha} \\
& \frac{\mathrm{K}_{2}}{\phi_{2}}=\alpha \Rightarrow \phi_{2}=\frac{\mathrm{K}_{2}}{\alpha}
\end{aligned}
$$

Substituindo-se as eq. [A5] e [A6] nas eq. [A3] e [A4] respectivamente, resulta um sistema de duas equaçōes com três incógnitas, $\mathrm{K}_{1}, \mathrm{~K}_{2}$, e $\alpha$ :

$$
\begin{aligned}
& \mathrm{q}_{1}=\mathrm{K}_{1}+\frac{4 \mathrm{~K}_{1}}{\pi \mathrm{r} \alpha} \\
& \mathrm{q}_{2}=\mathrm{K}_{2}+\frac{4 \mathrm{~K}_{2}}{\pi \mathrm{r} \alpha}
\end{aligned}
$$

Calculando a diferença $\left(\phi_{1}-\phi_{2}\right)$ a partir da eq. [A2], temos:

$$
\begin{gathered}
\phi-\phi_{2}=\int_{\tau_{\mathrm{i}}}^{\tau_{1}} \mathrm{~K}(\tau) \mathrm{d} \tau-\int_{\tau_{\mathrm{i}}}^{\tau_{2}} \mathrm{~K}(\tau) \mathrm{d} \tau \\
\phi-\phi_{2}=\left(\frac{\mathrm{K}_{1}+\mathrm{K}_{2}}{2}\right) \Delta \tau \quad \text { (extensao numerica) }
\end{gathered}
$$

Calculando a diferença $\left(\phi_{1}-\phi_{2}\right)$ a partir das eq. [A5] e [A6]:

$$
\phi_{1}-\phi_{2}=\frac{\mathrm{K}_{1}}{\alpha}-\frac{\mathrm{K}_{2}}{\alpha}=\frac{\mathrm{K}_{1}-\mathrm{K}_{2}}{\alpha}
$$

Igualando a eq. [A10] à eq. [A9]: 


$$
\frac{\mathrm{K}_{1}-\mathrm{K}_{2}}{\alpha}=\left(\frac{\mathrm{K}_{1}+\mathrm{K}_{2}}{2}\right) \Delta \tau
$$

Isolando $K_{1}$ na eq. [A7], $K_{2}$ na eq. [A8] e $\alpha$ na eq. [A11]:

$$
\begin{gathered}
\mathrm{q}_{1}=\mathrm{K}_{1}+\left(\frac{4 \mathrm{~K}_{1}}{\pi \mathrm{r} \alpha}\right)=\mathrm{K}_{1}\left(1+\frac{4}{\pi \mathrm{r} \alpha}\right) \Rightarrow \mathrm{K}_{1}=\frac{\mathrm{q}_{1}}{1+\frac{4}{\pi \mathrm{r} \alpha}} \\
\mathrm{q}_{2}=\mathrm{K}_{2}+\left(\frac{4 \mathrm{~K}_{2}}{\pi \mathrm{r} \alpha}\right)=\mathrm{K}_{2}\left(1+\frac{4}{\pi \mathrm{r} \alpha}\right) \Rightarrow \mathrm{K}_{2}=\frac{\mathrm{q}_{2}}{1+\frac{4}{\pi \mathrm{r} \alpha}} \\
\frac{\mathrm{K}_{1}-\mathrm{K}_{2}}{\alpha}=\left(\frac{\mathrm{K}_{1}+\mathrm{K}_{2}}{2}\right) \Delta \tau \Rightarrow \alpha=\frac{2\left(\mathrm{~K}_{1}-\mathrm{K}_{2}\right)}{\Delta \tau\left(\mathrm{K}_{1}+\mathrm{K}_{2}\right)}
\end{gathered}
$$

As eq. [A12], [A13] e [A14] formam um sistema de três equações e três incógnitas $\left(K_{1}, K_{2}, e \alpha\right)$. Substituindo as eq. [A12] e [A13] em [A14]:

$$
\begin{gathered}
\alpha=\frac{2\left[\frac{\mathrm{q}_{1}}{1+\frac{4}{\pi \mathrm{r} \alpha}}-\frac{\mathrm{q}_{2}}{1+\frac{4}{\pi \mathrm{r} \alpha}}\right]}{\Delta \tau\left[\frac{\mathrm{q}_{1}}{1+\frac{4}{\pi \mathrm{r} \alpha}}+\frac{\mathrm{q}_{2}}{1+\frac{4}{\pi \mathrm{r} \alpha}}\right]}=\frac{2 \times\left[\frac{\mathrm{q}_{1}-\mathrm{q}_{2}}{1+\frac{4}{\pi \mathrm{r} \tau}}\right]}{\Delta \tau\left[\frac{\mathrm{q}_{1}+\mathrm{q}_{2}}{1+\frac{4}{\pi \mathrm{r} \tau}}\right]} \Rightarrow \\
\Rightarrow \alpha=\frac{2\left(\mathrm{q}_{1}-\mathrm{q}_{2}\right)}{\Delta \tau\left(\mathrm{q}_{1}+\mathrm{q}_{2}\right)}
\end{gathered}
$$

$\mathrm{K}_{1}$ e $\mathrm{K}_{2}$ podem ser calculados substituindo-se $o$ valor de $\alpha$ obtido da eq. [A15] nas equações [A12] e [A13] respectivamente. 
2 Determinação da condutividade hidráulica utilizando dois infiltrômetros de disco de raios diferentes, $r_{1}$ e $r_{2}$, numa tensão $\tau$

A partir das medidas de fluxo estacionário, $q_{1}$ e $q_{2}$ para uma tensão $\tau$, obtidas respetivamente de dois infiltrômetros de raio $r_{1}$ e $r_{2}$, o fluxo pode ser expresso utilizando a eq. [A1] resultando nas eq. [16] e [17]:

$$
\begin{aligned}
& \mathrm{q}_{1}=\mathrm{K}+\frac{4 \phi}{\pi \mathrm{r}_{1}} \\
& \mathrm{q}_{2}=\mathrm{K}+\frac{4 \phi}{\pi \mathrm{r}_{2}}
\end{aligned}
$$

Isolando $\phi$ na equação [A16],

$$
\phi=\frac{\left(q_{1}-K\right) \pi r_{1}}{4}
$$

Substituindo [A18] em [A17],

$$
\begin{gathered}
\mathrm{q}_{2}=K+\frac{4 \pi \mathrm{r}_{1}\left(\mathrm{q}_{1}-\mathrm{K}\right)}{4 \pi \mathrm{r}_{2}}=\mathrm{K}+\frac{\mathrm{r}_{1}\left(\mathrm{q}_{1}-\mathrm{K}\right)}{\mathrm{r}_{2}} \Rightarrow \\
\Rightarrow\left(\mathrm{q}_{2}-\mathrm{K}\right) \mathrm{r}_{2}=\left(\mathrm{q}_{1}-\mathrm{K}\right) \mathrm{r}_{1} \Rightarrow\left(\mathrm{q}_{1}-\mathrm{K}\right) \mathrm{r}_{1}-\left(\mathrm{q}_{2}-\mathrm{K}\right) \mathrm{r}_{2}=0 \\
\Rightarrow \mathrm{q}_{1} \mathrm{r}_{1}-K \mathrm{r}_{1}-\mathrm{q}_{2} \mathrm{r}_{2}+K \mathrm{r}_{2}=0 \Rightarrow \\
\Rightarrow K\left(\mathrm{r}_{2}-\mathrm{r}_{1}\right)=\mathrm{q}_{2} \mathrm{r}_{2}-\mathrm{q}_{1} \mathrm{r}_{1}
\end{gathered}
$$

sendo,

$$
\mathrm{K}=\frac{\mathrm{q}_{2} \mathrm{r}_{2}-\mathrm{q}_{1} \mathrm{r}_{1}}{\mathrm{r}_{2}-\mathrm{r}_{1}}
$$


O potencial de fluxo mátrico pode-se calcular como segue:

$$
\phi_{0}=\frac{\pi\left(q_{1}-q_{2}\right)}{4\left(\frac{1}{r_{1}}-\frac{1}{r_{2}}\right)}
$$

A sortividade $S_{0}$ é calculada a partir da expressão de White \& Sully (1987):

$$
\mathrm{S}_{0}^{2}=\frac{\phi_{0}\left(\theta_{0}-\theta_{\mathrm{n}}\right)}{\mathrm{b}}
$$

onde $\theta_{n}$ e $\theta_{0}$ são os conteúdos iniciais e finais de água. É razoável assumir que b 0,55 (White \& Sully, 1987). 


\section{REFERÊNCIAS BIBLIOGRÁFICAS}

AHUJA, R.L.; BARNES, B.B.; CASSEL, D.K.; BRUCE, R.R.; NOFZIGER, D.L. Effect of assumed unit gradient during drainage on the determination on unsaturated hydraulic conductivity and infiltration parameters. Soil Science, v.145, n.4, p.235$243,1988$.

ANKENY, M.D.; KASPAR, T.C.; HORTON, R. Desing for an automated tension infiltrometer. Soil Science Society of America Journal, v.52, p.893-896, 1988.

ANKENY, M.D.; KASPAR, T.C.; HORTON, R. Characterization of tillage and trafic effects on unconfined infiltration measurements. Soil Science Society of America Journal, v.52, p.837-840, 1990.

ANKENY, M.D.; AHMED, M.; KASPAR, T.C.; HORTON, R. Simple field method for determining unsaturated hydraulic conductivity. Soil Science Society of America Journal, v.55, p.467-470, 1991.

ARYA, L.M.; DIEROLF, T.S.; SOFYAN, A.; WIDJAJA-ADHI, I.P.G.; VAN GENUCHTEN, M.T. Field measurement of the saturated hydraulic conductivity of a macroporous soil whit unstable subsoil structure. Soil Science, v.163, n.11, p.841852, 1998.

BACCHI, O.O.S.; REICHARDT, K. On simple methods for unsaturated soil hydraulic conductivity determination. Scientia Agricola, v.50, n.2, p.326-328, 1993.

BLAKE, G.R.; HARTGE, K.H. Bulk density. In: KLUTE, A. (Ed.) Methods of soil analysis. Part I: Physical and mineralogical methods. Madison: American Society of Agronomy, 1986a. cap.13, p.363 - 375.

BLAKE, G.R.; HARTGE, K.H. Particle density. In: KLUTE, A. (Ed.) Methods of soil Analysis. Part I: Physical and mineralogical methods. Madison: American Society of Agronomy, 1986b. cap.14, p.377-382. 
BOUMA, J.; JONGERIUS, A.; BOERSMA, O.; JAGER, A.; SCHOONDERBEEK, D. The function of different types of macropores during saturated flow through four swelling soil horizons. Soil Science Society of America Journal, v.41, p.945-950, 1977.

BOUMA, J. Measuring the hydraulic conductivity of soil horizons with continuous macropores. Soil Science Society of America Journal, v.46, p.438-441, 1982.

BOUMA, J. Influence of soil macroporosity on environmental quality. Advances in Agronomy, v.46, p.1-37, 1991.

BRAKENSIEK, D.L.; ENGLEMAN, R.L.; RAWLS, J.W. Variation within texture classes of soil water parameters. Transactions of the ASAE, v.24, n.2, p.335-339, 1981.

BROOKS, R.H.; COREY T. Hydraulic properties of porous media., Fort Collins: Colorado State University, Hidrology papers, n.3, 27p, 1964.

CHAVES, H.M.L.; ORLOWSKI, E.; ROLOFF, G. Previsão da infiltração sob condições dinâmicas de selamento superficial. Revista Brasileira de Ciência do Solo, v.17, p.141-147, 1993.

CHEN, C.; THOMAS, D.M.; GREEN, R.E.; WAGENET, R.J. Two domain estimation of hydraulic properties in macropore soils. Soil Science Society of America Journal, v.57, p.680-686, 1982

CHILDS, E.C. An introduction to the physical basis of soil water phenomena. London: John Wiley, 1969. 493p.

CHONG, S.K.; GREEN, R.E.; AHUJA, L.R. Simple in situ determination of hydraulic conductivity by power function descriptions of drainage. Water Resources Research, v.17, n.4, p.1109-1114, 1981.

CHOW, V.T.; MAIDMENT, D. R.; MAYS, L. W. Aplied hydrology. New York: Mc. Graw Hill, 1988. 572 p.

CLAUSNITZER, V.; HOPMANS, J.W.; STARR, J.L. Parameter uncertainty analysis of common infiltration models. Soil Science Society of America Journal, v.62, p.1477-1487, 1998. 
CLOTHIER, B.E.; SMETTEM, K.R.J. Combining laboratory and field measurements to define the hydraulic properties of soil. Soil Science Society of America Journal, v.54, n.2, p.299-304, 1990.

COOK, F.J.; BROEREN, A. Six methods for determining sorptivity and hydraulic conductivity with disc permeameters. Soil Science, v.157, n.1, p.2-11, 1994.

DAVIDSON, J.M.; STONE, L.R.; NIELSEN, D.R.; LARUE, M.E. Field measurement and use of soil-water properties. Water Resources Research, v.5, n.6. p.13121321.

DIRKSEN, C.H. Unsaturated Hydraulic Conductivity. In: SMITH, K.A; MULLINS C.E., (Ed.) Soil analysis: physical methods. New York: Dekker, 1991. cap.5, p.209-269.

DOURADO NETO, D.; JONG VAN LIER, Q. de; BORTEL, T.A.; LIBARDI, P.L. Programa para confeção da curva de retenção de água no solo utilizando o modelo de Genutchen. Engenharia Rural, v.1, p.92-102, 1990.

DUNN, G.H.; PHILLIPS, R.E. Macroporosity of a well-drained soil under no-till and conventional tillage. Soil Science Society of America Journal, v.55, p.817-823, 1991.

ELRICK, D.E.; REYNOLDS, D.W. Infiltration from Constant-Head Well Permeameters and Infiltrometers. In: TOOP, G.C.; REYNOLDS, W.D. (Ed.) Advances in measurement of soil physical propieties: bringing theory into practice. Madison: American Society of Agronomy, 1992. cap.1, p.1 - 24.

EVERTS, C.J.; KANWAR, R.S. Interpreting tension infiltrometer data for quantifying soil macropores: some practical considerations. Trans. ASAE, v.36, n.2, p.423-427, 1992.

FALLEIROS, M.C.; PORTEZAN, O., OLIVEIRA, J.C.M.; BACCHI, O.O.S.; REICHARDT, K. Spatial and temporal variability of soil hydraulic conductivity in relation to soil water distribution, using an exponential model. Soil and Tillage Research, v.45, p.279-285, 1998. 
FAYBISHENKO, B.A. Hydraulic behavior of quasi-saturated soils in the presence of entrapped air: Laboratory experiments. Water Resources Research, v.31, n.10, p.2421-2435, 1995.

GARDNER, W.R. Some steady state solutions of the unsaturated moisture flow equation with application evaporation from a water table. Soil Science, v.85, p.228232, 1958.

GARDNER, W.T. Water Content. In: BLACK, C.A, (Ed.) Methods of soil analysis. Part I: Physical and mineralogical methods. Madison: American Society of Agronomy, 1986. p $493-541$.

GREEN, W.H. ; AMPT, G.A Studies in soil phisics I. The flow of air and water through soils. Journal of Agricultural Sciences, v.4, p. 1-24, 1911.

GUPTA, R.K.; RUDRA, R.P.; DICKINSON, W.T.; PATNI, N.K.; WALL, G.J. Comparison of saturated hydraulic conductivity measured by various field methods. Transactions of the ASAE, v.36, n.1, p.51-55, 1993.

GUROVICH, L.A.; GALO, R. ; JARMILLO J. Modelos matemáticos y mediciones experimentales en la determinación de infiltración de agua en el suelo. Ciencia e Investigación Agraria. Universidad Católica de Chile, v.4, n.3, p.197-207, 1977.

HILLEL, D.; KRENTOS, V.D.; STYLIANOU, Y. Procedure and test of an internal drainage method for measuring soil hydraulic characteristic in situ. Soil Science Society of America Journal, v.114, n.5, p.395-400, 1972.

HOPMANS, J.W.; CLAUSNITZER, V.; KOSUGI, K.I.; NIELSEN, D.R.; SOMMA, F. Vadose zone measurement and modeling. Scientia Agricola, v.54, p.22-38, 1997.

HORTON, R.E. Na aproach toward a physical interpretation of infiltration capacity. Soil Science Society of America Proceedings, n.5, p.399-417, 1940.

IWATTA, S.I.; TABUCHI, T. Soil-water interactions: mechanisms and applications. New York: Dekker, 1988. 380p. 
JARVIS, N.J. \& MESSING, I. Near-saturated hydraulic conductivity in soils of contrasting texture measured by tension infiltrometers. Soil Science Society of America Journal, v.59, p.27-34, 1995.

KLUTE, A. Water retention: laboratory methods. In: KLUTE, A. (Ed.). Methods of Soil Analysis, I. Physical and mineralogical methods. Madison: American Society of Agronomy, 1986. cap.26, p.635-660.

KLUTE, A.; DIRKSEN, C.H. Hydraulic conductivity and diffusivity: Laboratory methods. In: KLUTE, A. (Ed.). Methods of Soil Analysis, I. Physical and mineralogical methods. Madison: American Society of Agronomy, 1986. cap.28, p.687-732.

KOSTIAKOV, A N. On dynamics of the coefficient of water percolation in soils and on the necessity for studying it fron a dynamic point of view of purposes of amelioreton. Trans $6^{\text {th }}$ comm. Intern. Soc Soil Sci., Moscou, Part A, p.17-21, 1932.

KUTÍLEK, M.; NIELSEN, D.R. Soil hydrology. Alemania: Catena Verlag, 1994. 370p.

LAUREN, J.G.; WAGENET, R.J.; BOUMA, J.; WOSTEN, J.H.M. Variability of saturated hydraulic conductivity in a glossaquic hapludalf with macropores. Soil Science, v. 145, n. 1, p. $20-28,1988$.

LIBARDI, P. Dinâmica da água no solo. Piracicaba : O autor, 1995. 497 p.

LIBARDI, P.; REICHARDT, K.; NIELSEN,D.P.; BIGGAR, J.W. Simple field methods for estimating soil hydraulic conuctivity. Soil Science Society of America Journal, v.44, p.3-7, 1980.

LOGSDON, S.D.; JAYNES, D.B. Methodology for determining hydraulic conductivity with tension infiltrometers. Soil Science Society of America Journal, v.57, n.6, p.1426-1431, 1993.

LOGSDON, S.D. Negative head hydraulic properties of the soil surface at different times. Soil Science, v.156, n.6, p.373-379, 1993.

LOGSDON, S.D.; JORDAHL, J.L.; KARLEN, D.L. Tillage and crop effects on ponded and tension infiltration rates. Soil and Tillage Research, v.28, n.2, p.179-189, 1993. 
MARION, J.M.; OR, D.; ROLSTON, D.E.; KAWAS, M.L.; BIGGAR, J.W. Evaluation of methods for determining soil water retentivity and unsatureted hydraulic conductivity. Soil Science, v.158, n.1, p.1-13, 1994.

MBAGWU, J.S.C. Testing the goodness of fit of infiltration models for highly permeable soils under different tropical soil management systems. Soil and Tillage Research, v.34, p.199-205, 1995.

MCCOY, E.L.; BOAST, C.W.; STEHOUWER, R.C.; KLADIVKO, E.J. Macropore hydraulics: taking a sledgehammer to classical theory. Advances in soil science, v.47, p.303-348, 1994.

MEIN, R.G.; LARSON, C.L. Modeling infiltration during steady rain. Water Resources Research, v.9, n.2, p.384-394, 1973.

MIYAZAKI, T. Water flow in soils. New York: Marcel Dekker, 1993. 296p.

MOHANTY, B.P.; KANWAR, R.S.; EVERTS, C.J. Comparison of saturated hydraulic conductivity measurement methods for a glacial-till soil. Soil Science Society of America Journal, v.58; p.672-677; 1994.

MOHANTY, B.P.; SKAGGS, T.H.; van GENUCHTEN, M.T. Impact of saturated hydraulic conductivity on the prediction of tile flow. Soil Science Society of America Journal, v.62; p.1522-1529; 1998.

MORAES, S.O. Heterogeneidade hidráulica de uma terra roxa estruturada. Piracicaba, 1991. 141p. Tese (Doutorado) - Escola Superior de Agricultura Luiz de Queiroz, Universidade de São Paulo.

MUALEM, Y. A new model for predicting the hydraulic conductivity of unsaturated porous media. Water Resources Research, v.12, n.3, p.513-522, 1976.

MWENDERA, E.J.; FEYEN, J. Tillage and rainfall effects on infiltration and predictive aplicability of infiltration equations. Soil Science, v.156, n.1, p.20-27, 1993.

OTHMER, H.; DIEKKRÜGER, B.; KUTILEK, M. Bimodal porosity and unsaturated hydraulic conductivity. Soil Science, v.152, n.3, p.139-150, 1991. 
PAIGE, G.B.; HILLEL, D. Comparison of three methods for assesing soil hydraulic properties. Soil Science, v.155, n.3, p.175-189, 1991

PARLANGE, J.Y.; LISLE, I.; BADDOCK, R.D.; SMITH, R.E. The three-parameter infiltration equation. Soil Science, v.133, p.337-341, 1982.

PERROUX, K.M.; WHITE, I. Desings for disk permeameters. Soil Science Society of America Journal, v.52, n.5, p.1205-1215, 1988.

PHILIP, J.R. Numerical solution of equations of the diffusion type with diffusivity concentration dependent. Australian Journal of. Physics, v.2, n.10, p.29-42, $1957 a$.

PHILIP, J.R. The theory of infiltration 4. Sorptivity and algebraic infiltration equations. Soil Science, v.84 p.257-264, 1957 b.

PHILIP, J.R. The theory of infiltration. Advances in hydroscience, v.5 p.215-296, 1969.

RAATS, P.A.C.; GARDNER, W.R. Comparison of empirical relationships between pressure head and hydraulic conductivity and some observations on radially simetric flow. Water Resources Research, v.7, n.4, p.921-927, 1971.

RAWLS, W.J.; BRAKENSIEK, D.L. 1986. Comparison Between Green-Ampt and curve number runoff predictions. Transactions of the ASAE, v.29, n.6, p.1597-1599, 1986.

REICHARDT, K. Unit gradient in internal drainage experiments for the determination of soi hydraulic conductivity. Scientia Agricola, v.50, n.1, p.151-153, 1993.

REICHARDT, K.; PORTEZAN, O.; LIBARDI, P.L.; BACCHI, O.O.S.; MORAES, S.O.; OLIVEIRA, J.C.M.; FALLEIROS, M.C. Critical analysis of the field determination of soil hydraulic conductivity functions using the flux-gradient approach. Soil and Tillage Research, v.48, p.81-89, 1998.

SCHUH, W.M.; BAUDER, J.W.; GUPTA, S.C. Evaluation of simplified methods for determining unsaturated hydraulic conductivity of layered soils. Soil Science Society of America Journal, v.48, p.730-736, 1984. 
SCOTTER, D.R.; CLOTHIER, B.E.; HARPER, E.R. Measuring saturated hydraulic conductivity and sorptivity using twing rings. Australian Journal of Soil Research, v.20, p.295-304, 1982.

SISSON, J.B.; FERGUSON. A.H.; VAN GENUCHTEN, M.T. Simple method for predicting drainage from field plots. Soil Science Society of America Journal, v.44, p.1147-1152, 1980.

SKAGGS, R. W.; KHALEEL R. Infiltration. In: HAAN, C. T.; JHONSON, H. P.; BRAKENSIEK, D. L. (Ed.) Hidrologic modeling of small watersheds. St. Joseph: ASAE, 1982. $533 \mathrm{p}$.

SMETTEM, K.R.J.; CLOTHIER, B.E.. Measuring unsaturated sorptivity and hydraulic conductivity using multiple disc permeameters. Journal of Soil Science, v.40, p.563-568, 1989.

SWARTZENDRUBER, D. A quasi-solution of Richard's equation for the downward infiltration into soil. Water Resources Research, v.23, p.809-817, 1987.

SWARTZENDRUBER, D.; YOUNGS, E.G. A comparison of physically-based infiltration equations. Soil Science, v.117, n.3, p.165-167, 1974.

TIMLIN, D.J.; AHUJA. L.R.; ANKENY, M.D. Comparison of three field methods to characterize apparent macropore conductivity. Soil Science Society of America Journal, v.58, p.278-284, 1994.

VAN GENUCHTEN, M.T. A closed-form equation for predicting the hydraulic conductivity of unsaturated soils. Soil Science Society of America Journal, v.44, p.892-898, 1980.

WARRICK, A.W.; NIELSEN, D.R. Spatial variability of soil physical properties in the field. In: HILLEL, D. (Ed.) Applications of soil physics. New York: Academic Press, 1980. cap. 13, p. 319-344

WARRICK, A.W. Models for disc infiltrometers. Water Resources Research, v.28, n.5, p.1319-1327, 1992. 
WATSON, K.W.; LUXMOORE, R.J. Estimating macroporosity in a forest watershed by use of a tension infiltrometer. Soil Science Society of America Journal, v.50, n.3, p.578-582, 1986.

WELLS, L.G.; WARD, D.; MOORE, I. D.; PHILIPS, R.E. Comparison of four infiltration models in characterizing infiltration through surface mine profiles. Transactions of the ASAE, v.29, n.3, p.785-793, 1986.

WHITE, I.; PEROUX, K.M. Estimation of unsaturated hydraulic conductivity from field sorptivity measurements. Soil Science Society of America Journal, v.53, p.324329, 1989.

WHITE, I.; SULLY, M.J. Macroscopic and microscopic capillary length and time scales from field infiltration. Water Resources Research, v.23, n.8, p.1514-1522, 1987.

WHITE, I.; SULLY, M.J.; PEROUX, K.M. Use of sorptivity to determine field soil hydraulic properties. Soil Science Society of America Journal, v.51, n.5, p.1093$1101,1987$.

WHITE, I.; SULLY, M.J.; PEROUX, K.M. Measurement of surface-soil hydraulic propieties: disk permeameters, tension infiltrometers, and other techniques. In: TOOP, G.C.; REYNOLDS, W.D. (Ed.) Advances in measurement of soil physical propieties: bringing theory into practice. Madison: American Society of Agronomy, 1992. cap.6, p.69 - 99.

WILSON, G.V.; LUXMOORE, R.J. Infiltration, macroporosity, and mesoporosity distributions on two forested watersheds. Soil Science Society of America Journal, v.52, p.329-335, 1988.

WOODING, R.A. Steady infiltration from a shallow circular pond. Water Resourses Reserarch, v.4, n.6, p.1259-1273, 1968.

YOUNGS, E.G. Hydraulic conductivity of saturated soils. In: K.A SMITH; MULLINS, C.E. (Ed). Soil analysis: physical methods. New York: Marcel Dekker. 1991. p.161-207.

YOUNGS, E.G. Developments in the physics of infiltration. Soil Science Society of America Journal, v.59, p.307-313, 1995. 
APÊNDICE 1 

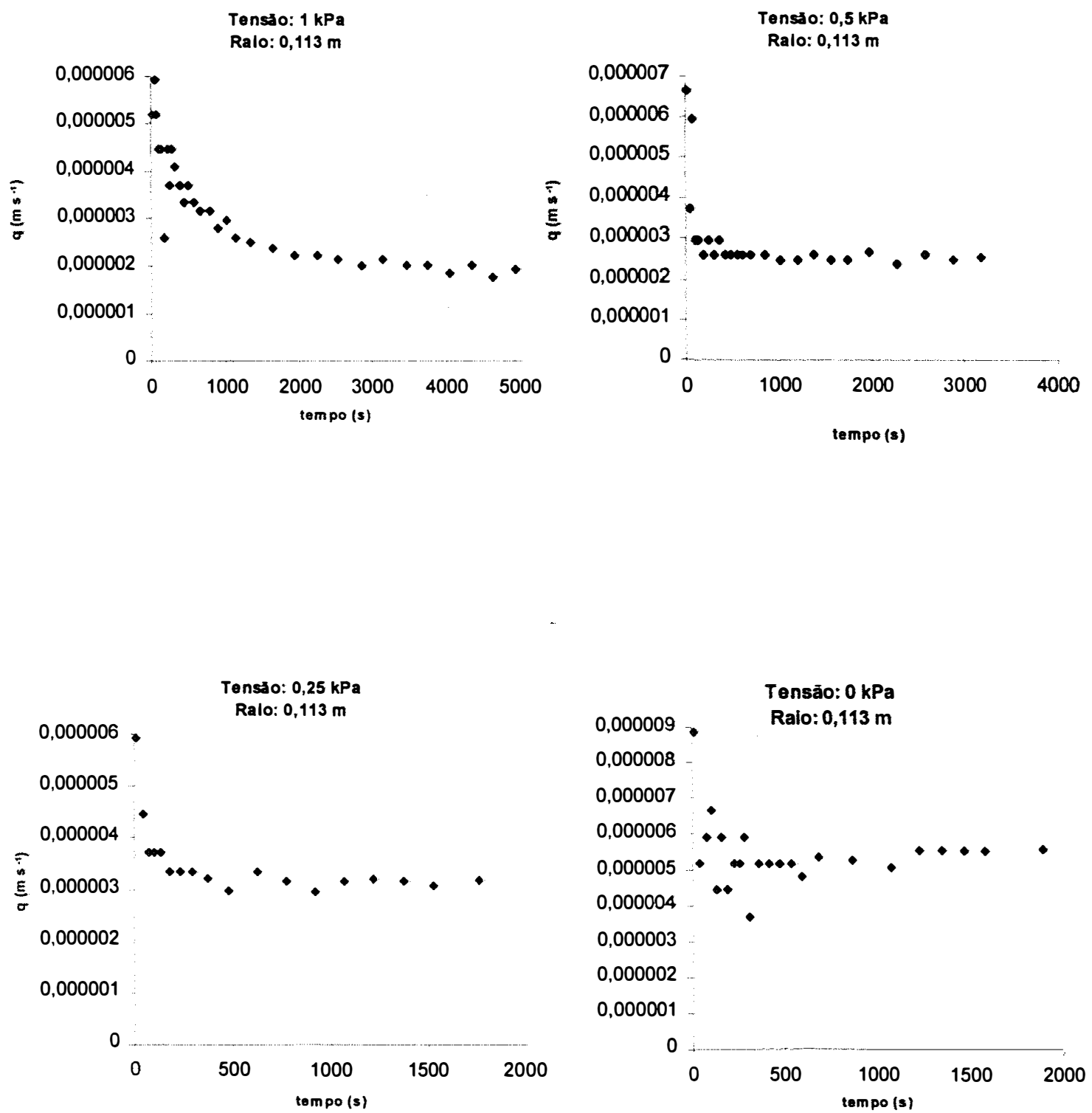

Apêndice 1.1 - Fluxo medido em função do tempo utilizando o infiltrômetro de tensão de base maior. Os dados correspondem à repetição 4 



Apêndice 1.2 - Fluxo medido em função do tempo utilizando o infiltrômetro de tensão de base menor. Os dados correspondem à repetição 4 